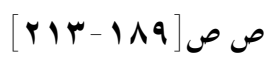

\author{
الإستر اتيجية التقنية والميزة التنافسية في الألفية الثالثة: \\ مدخل القيمة المضافة فئة \\ در اسة نظرية \\ عامر عبدالرزاق عبدالخسن الجبوري \\ مدرس مساعد - قسم نظم المعلومات الإدارية

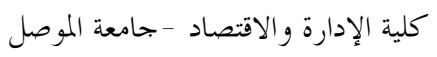 \\ amer_alnasser2002@yahoo.com
}

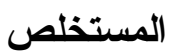

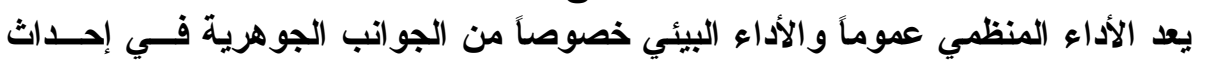

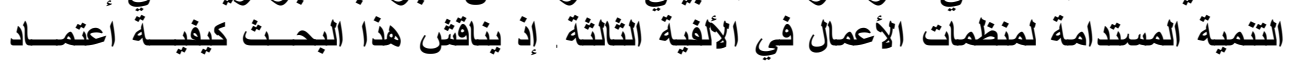

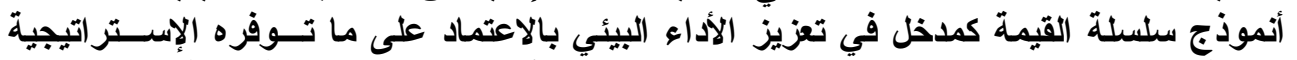

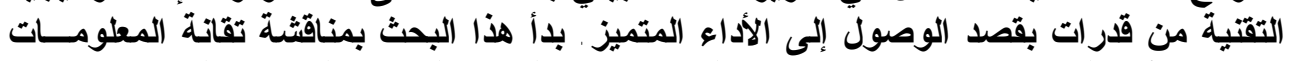

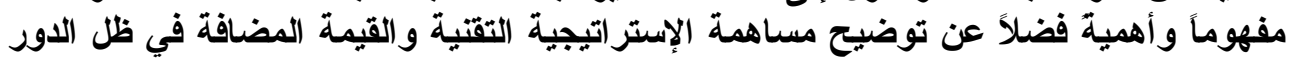

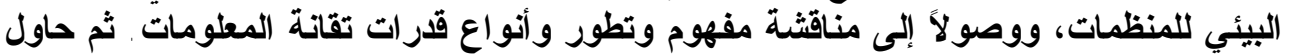

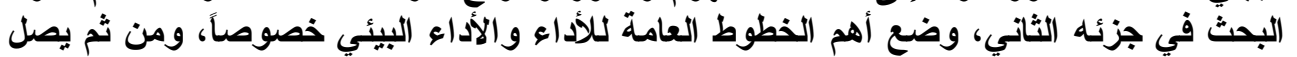

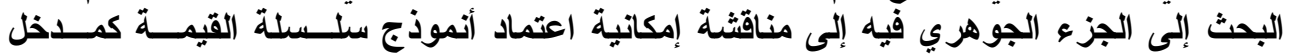

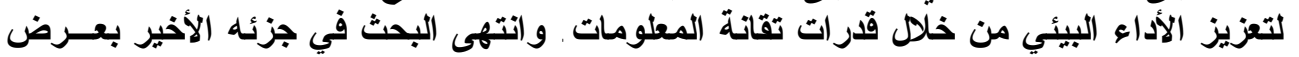

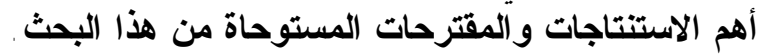

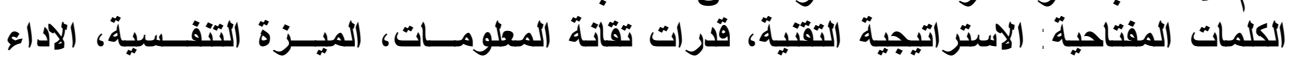
البيئي، سلسلة القيمة.
\end{abstract}




\title{
The Technological Strategy and Competitive Advantage in the Third Millennium: Approach of Added Value Theoretical Study
}

\author{
Amir A. Aljibouri \\ Assistant Lecturer \\ Department of Management Information Systems \\ College of Administration \& Economics -University of Mosul \\ amer_alnasser2002@hotmail.co.uk
}

\begin{abstract}
The organizational performance in general and the environmental performance in particular are considered to be part of the fundamental aspects in bringing about sustainable development in business organizations during Third Millennium. This research discusses ways of how to adopt model of Value Chains as approaches in reinforcing the environmental performance by relying on the capabilities provided by technical strategies, in achieving excellence performance. This research started with discussing the concept of Information Technology (IT) and its importance, in addition to explain the contribution of the technological strategy and Added Value under the environmental role of the organizations; as well as discussing the concepts of IT capabilities, their development and types. In its second part, the research tried to state the most important general guidelines of the Organizational Performance and especially the Environmental Performance. To arriving at its essential issue, the discussion of the adoption of the model of Value Chain as an approach to reinforcing the environmental performance through the use of IT capabilities. Finally, the research ended by stating the most important conclusions and suggestions that have been reached by this research.

Key words: Technological Strategy, Information Technology Capabilities, Competitive Advantage, Environmental Performance, Value Chain.

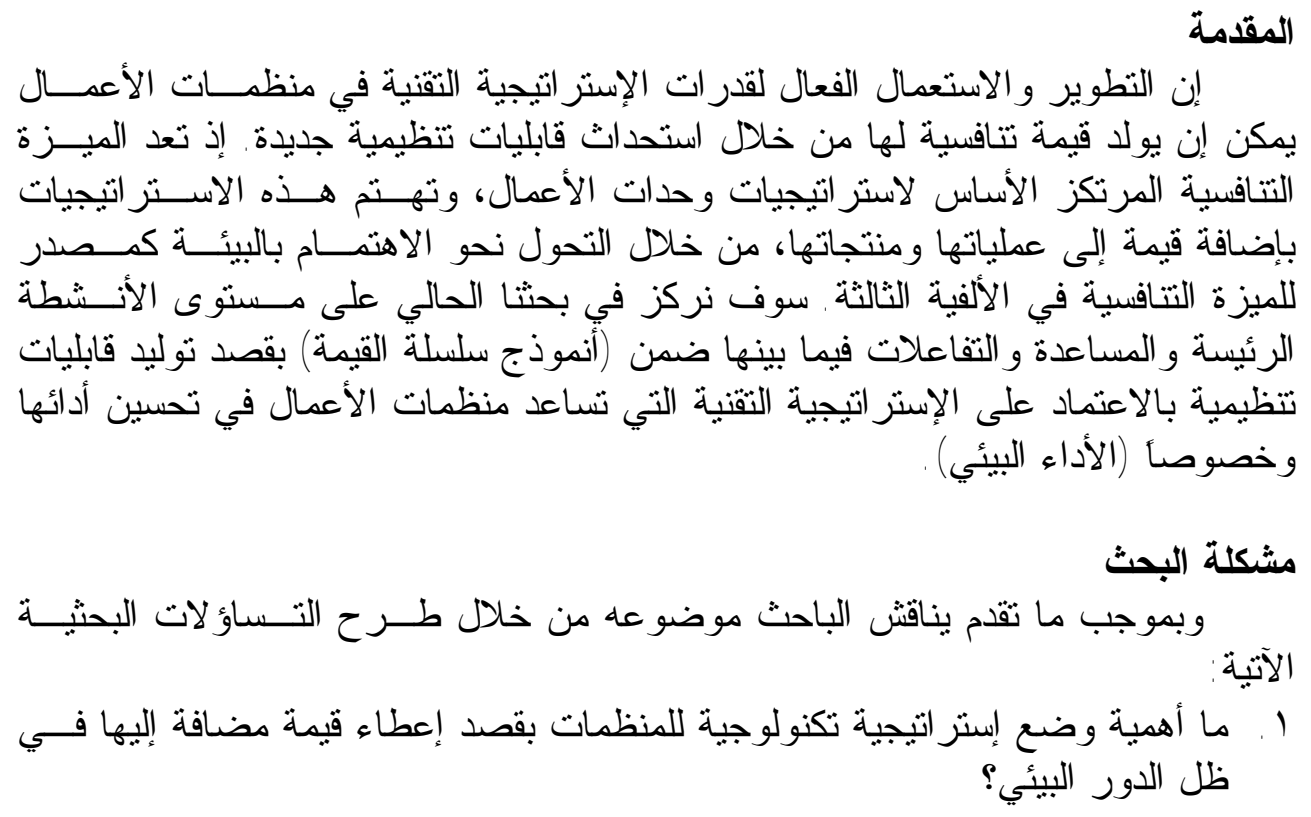


الجبوري[191] [-

r . . ما المقصود بتقانة المعلومات؟ وما هي قدر اتها المعتمدة في تعزيز الأداء؟

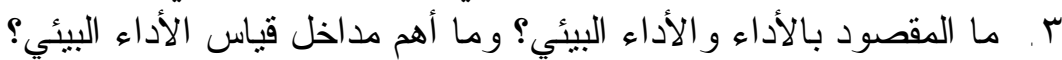

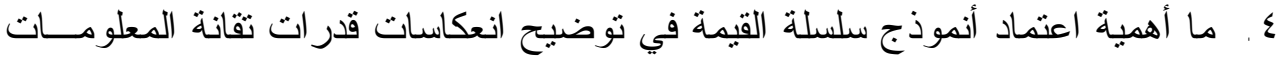
على الأداء البيئي? أباد

$$
\text { يهدف البحث إلى تحقيق الآتي: }
$$

أهداف البحث

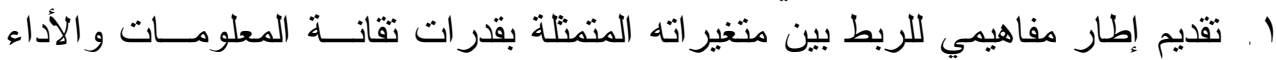

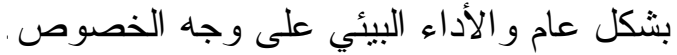

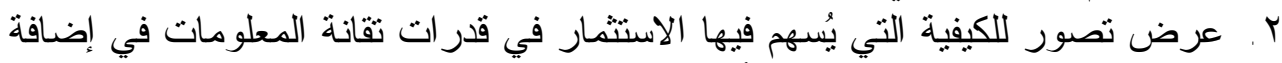

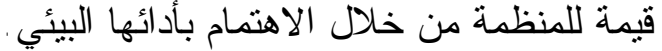

تتجلى أهمية البحث في زيادة إدر الك المديرين في الإدارة العليا لمنظمات الأعمـال

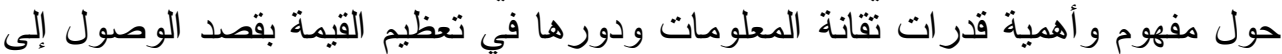

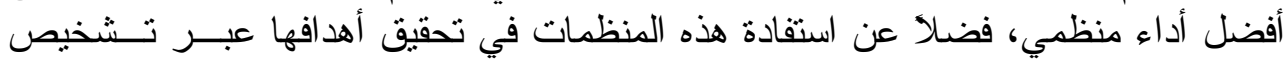

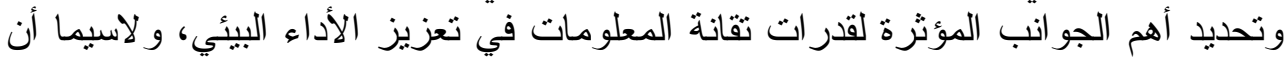

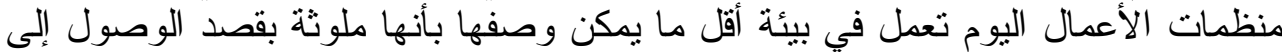

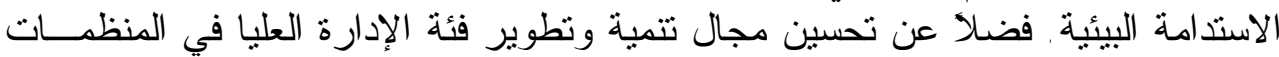

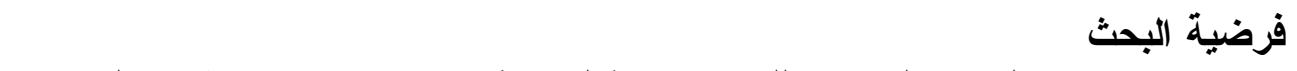

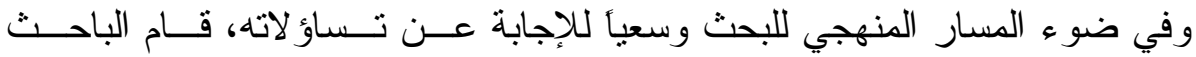

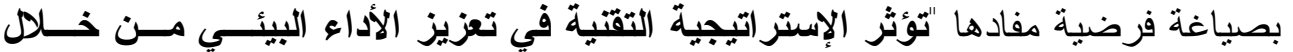

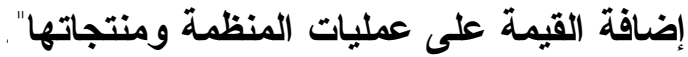

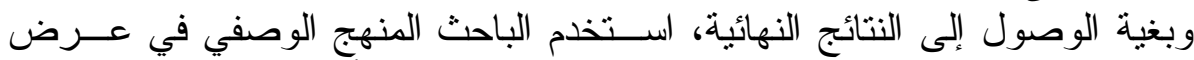

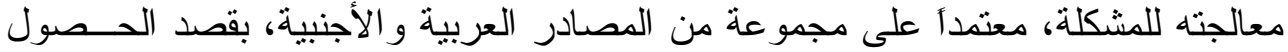

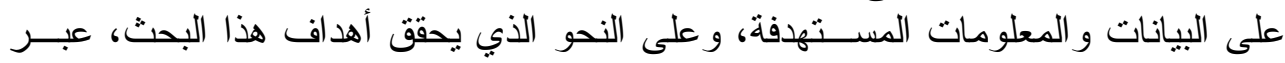

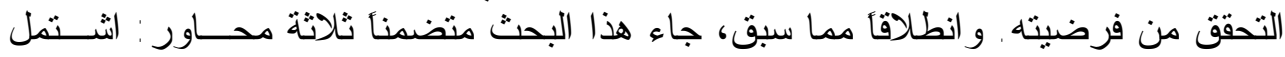

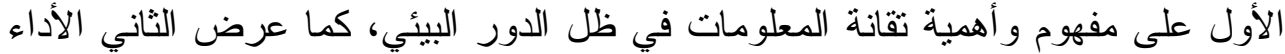

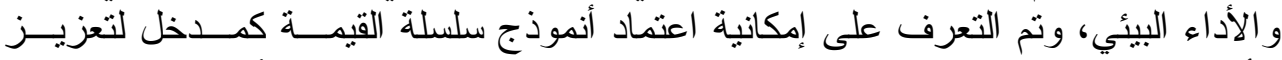

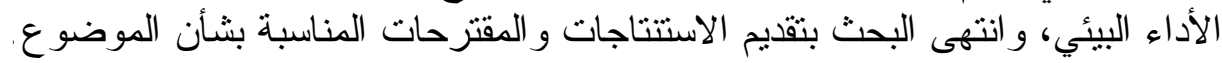

Information Technology تقاتة المعلومات

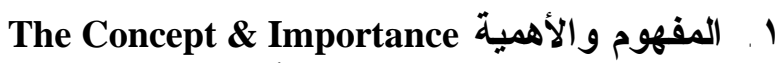

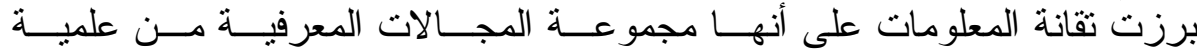

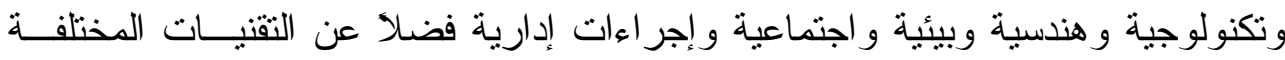

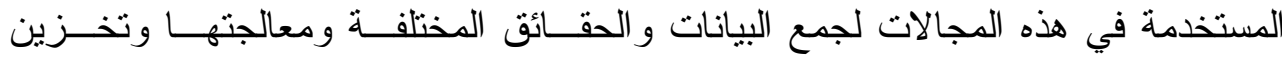


المعلومات ونقلها وبثها و استرجاعها، فهي التقانة التي نركز على المعلومات و المعرفة في

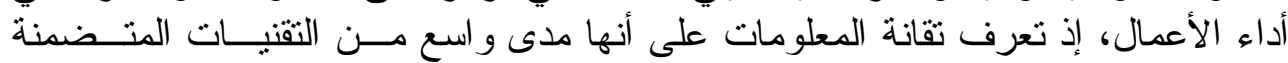

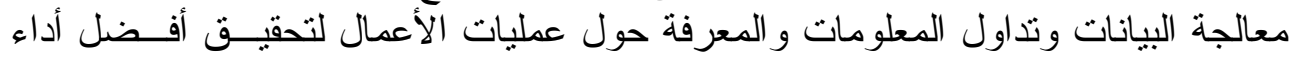

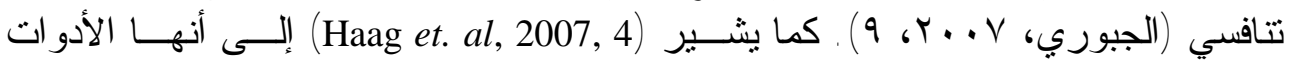

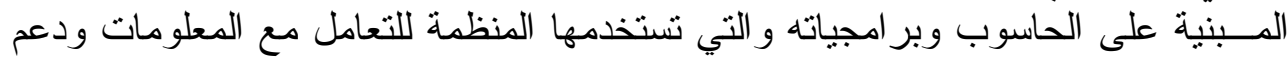

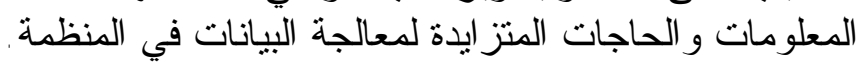

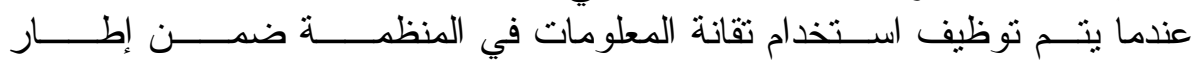

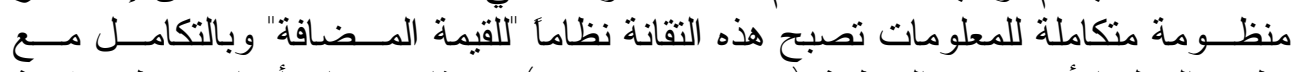

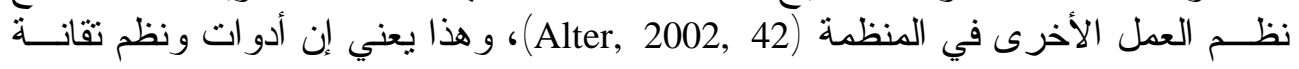

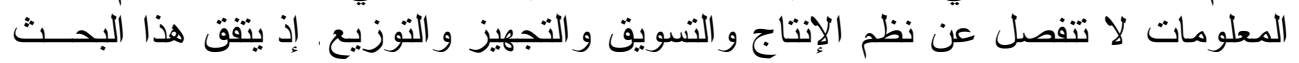

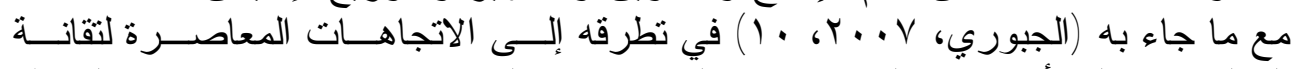

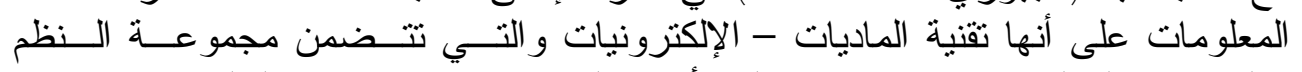

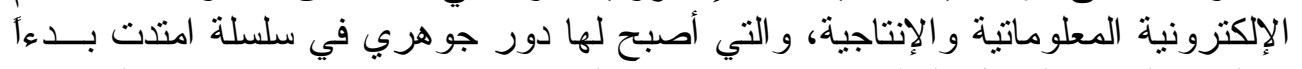

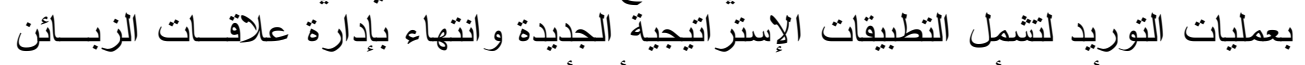

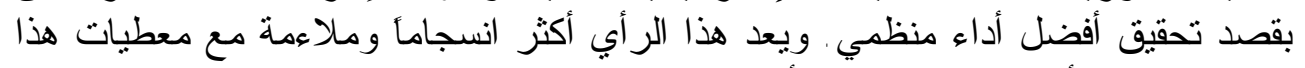

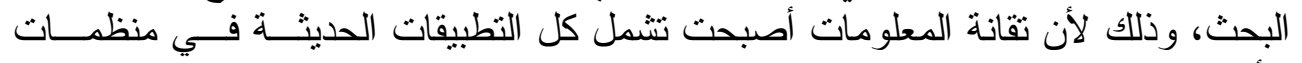

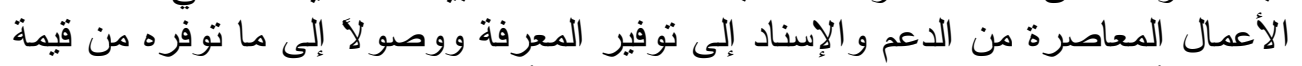

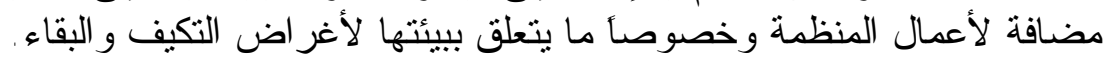

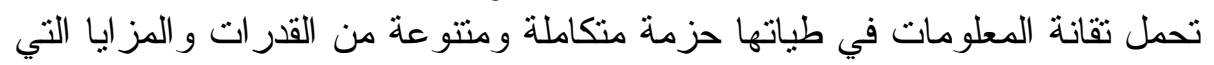

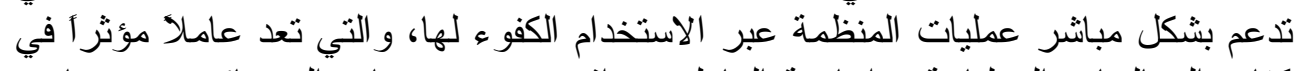

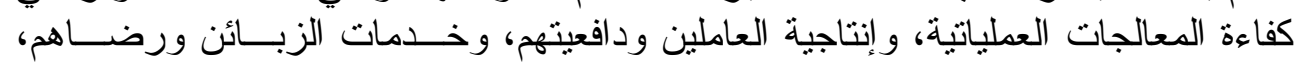

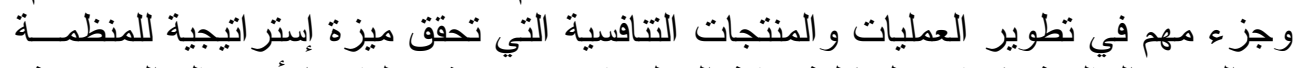

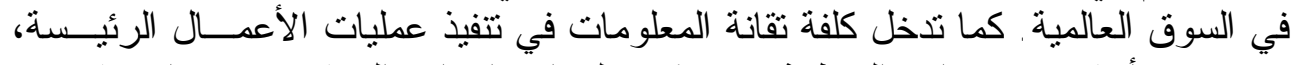

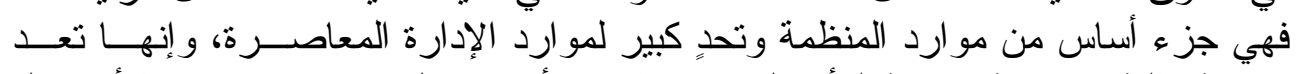

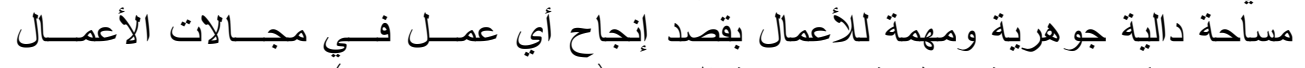

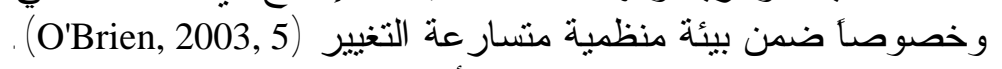

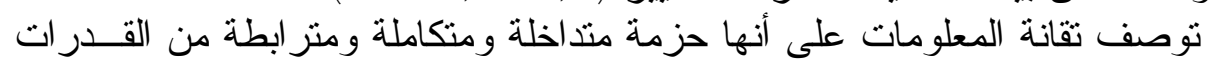

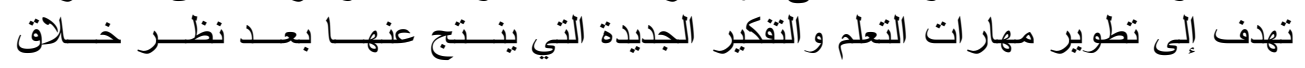

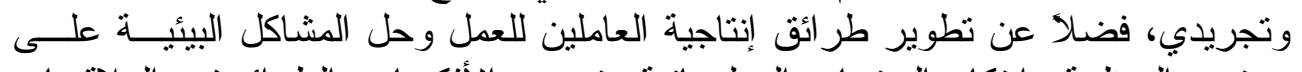

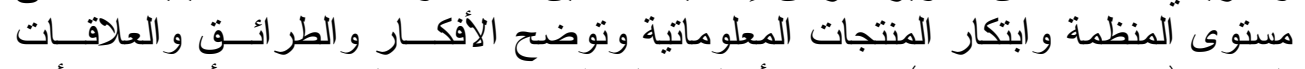

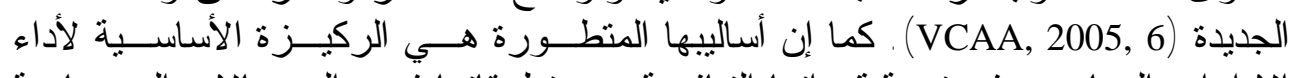

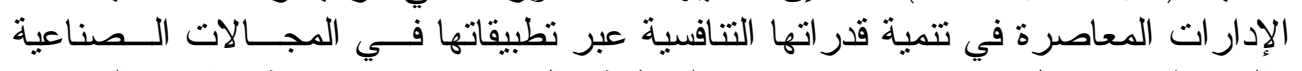

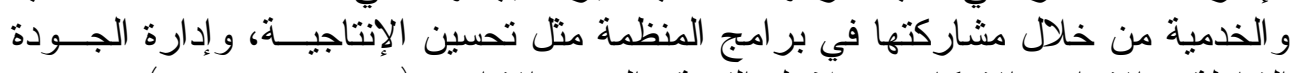
الثاملة، و الإبداع و الابتكار ، وسلاسل الثل القيمة و التغيير الإداري (Daft, 2003, 240) .

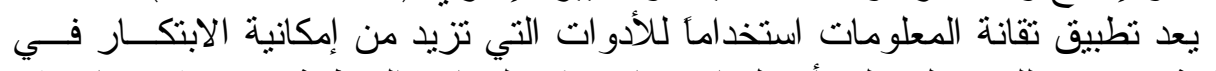

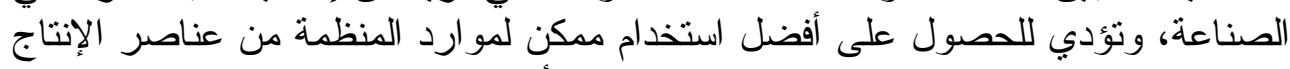

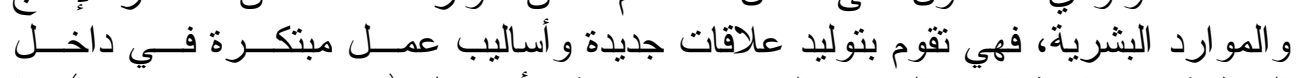

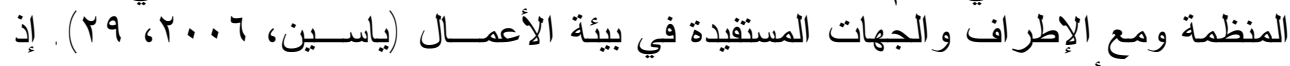

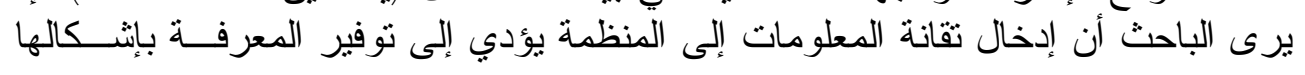


[الجبوري[19r]

كافة وبالأخص المعرفة الحاسمة ونشر ها إلى المستفيدين منها داخل المنظمة لتحقيق الأداء

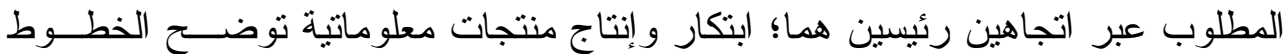

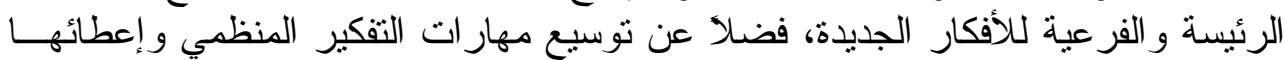
بعدأ مستقبلياً.

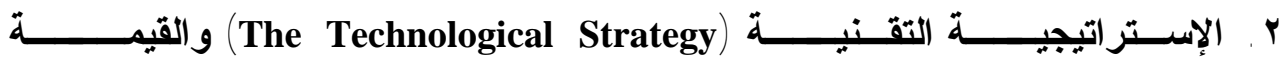

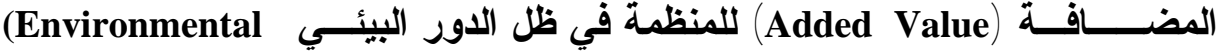

:Role)

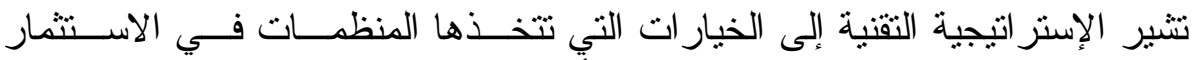

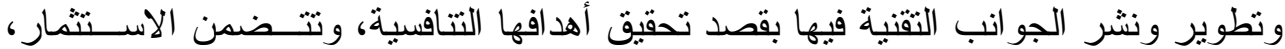

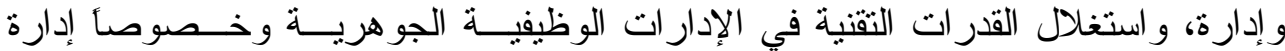

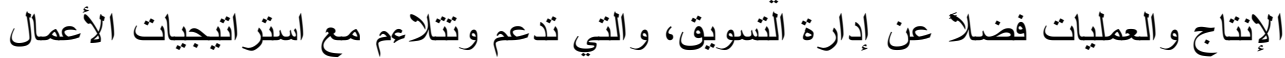

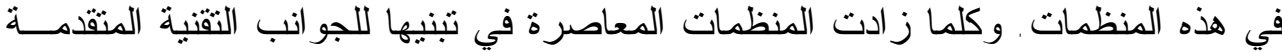

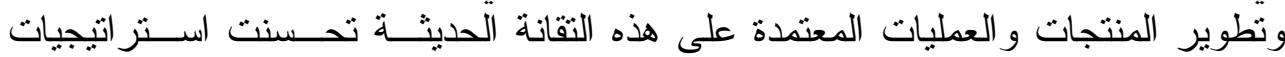

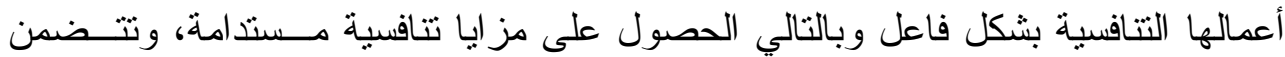

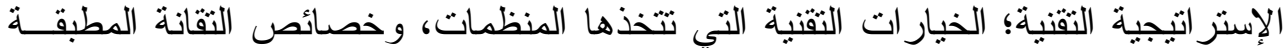

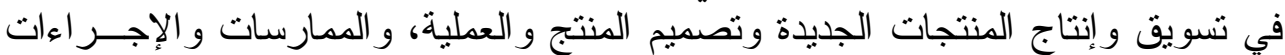

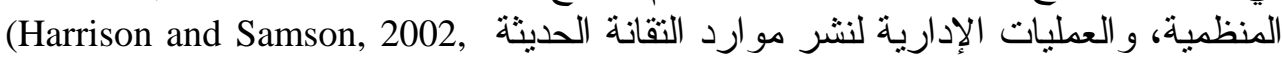

و عند توضيح الإستر اتيجية التقنية لابد من التعرف على نقاط جو هرية منها الــنظم

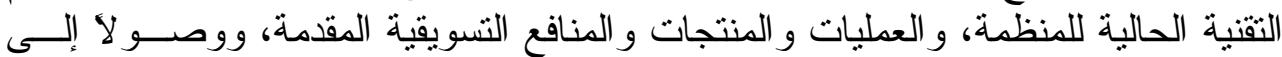

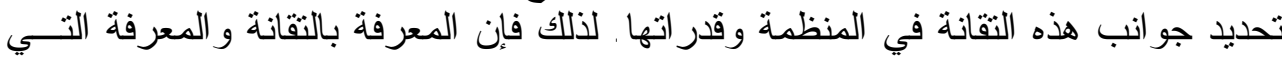

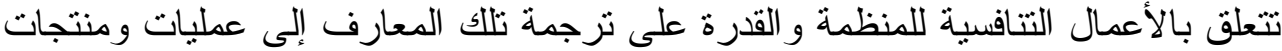

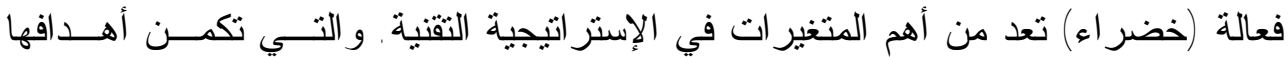

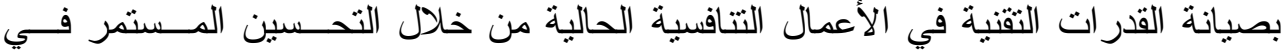

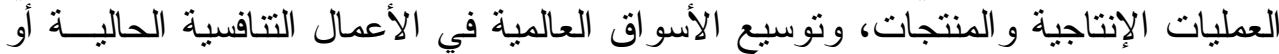

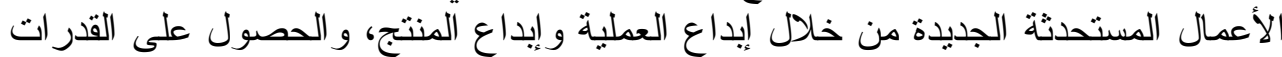

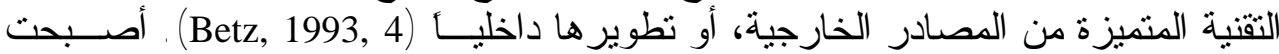

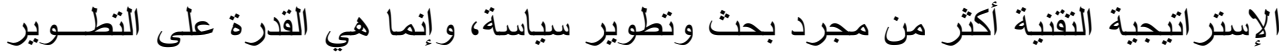

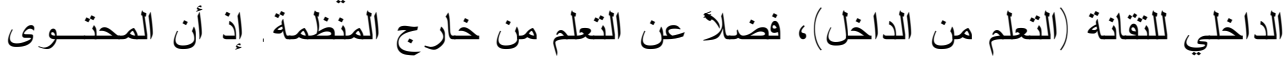

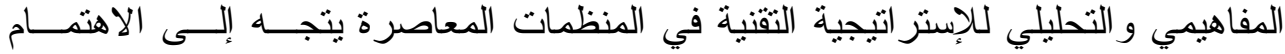

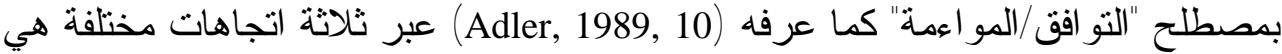

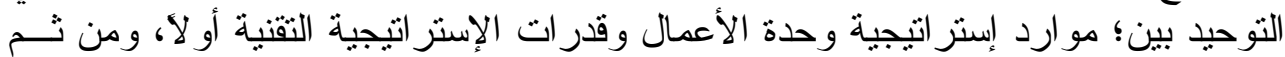

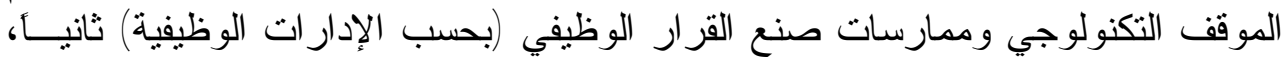

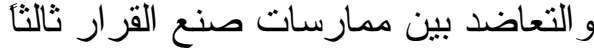

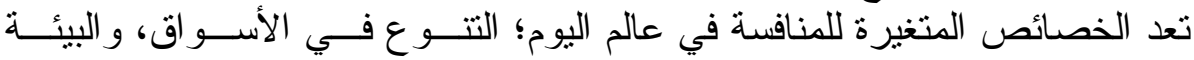

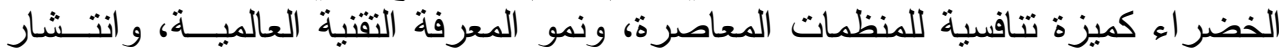

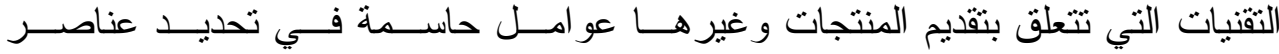
الإستر اتيجية التقنية داخل المنظمة مثل (نوع التقانة المستخدمة، وصف مستوى القــــــات 


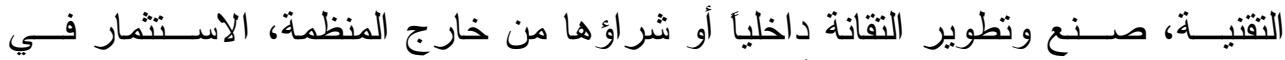

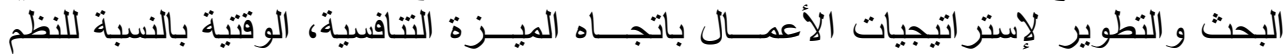

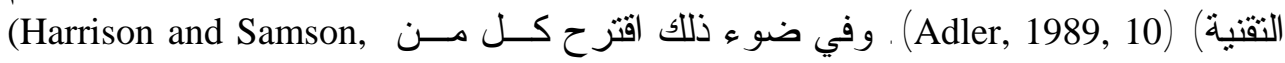

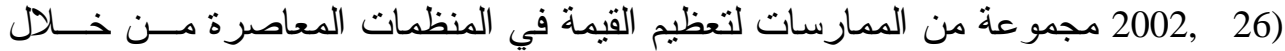

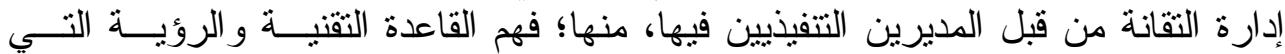

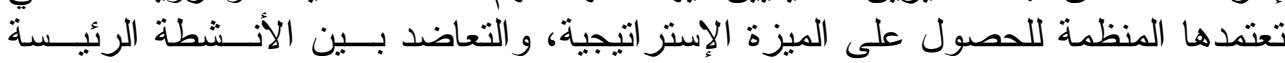

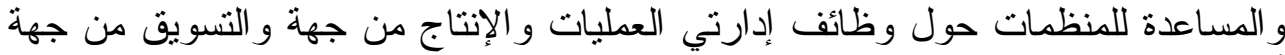

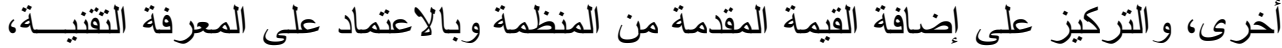

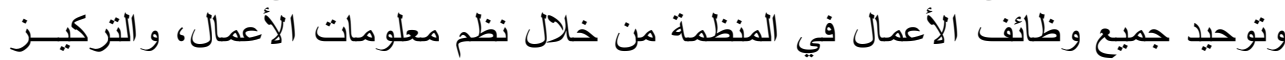

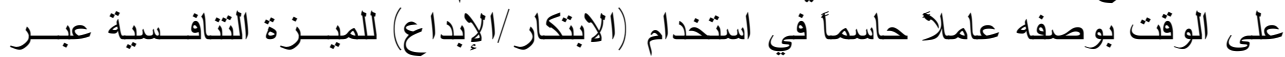

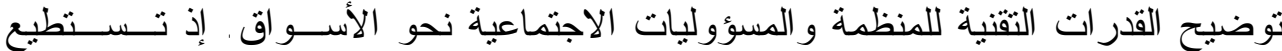

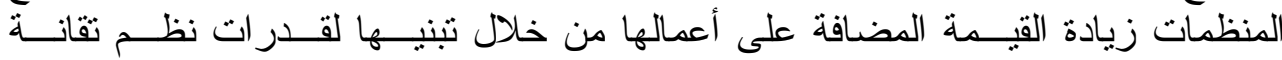

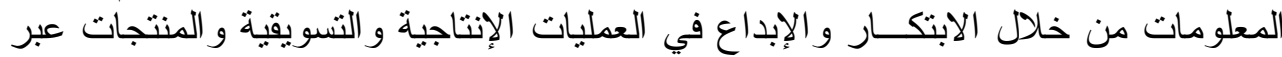

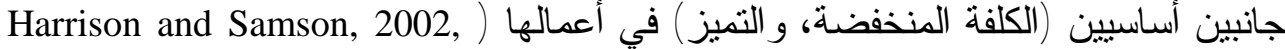
26) ، والجدول ( يوضح بعض الأمتلة لنظم تقانة المعلومات التي تساعد في تعزيز القيمة

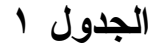

بعض الأمثلة لنظم تقانة المعلومات التي تساعد في تعزيز القيمة المضافة

\begin{tabular}{|c|c|c|c|}
\hline الابتكار والإبداعية في العمليات & الابتكار والإبداع في العمليات & الابتكار والإبداع في المنتجات & التأثير \\
\hline نظم التجم التسويق الإلكترونية الإلكترونية & نظم نظم سنطرة العملية العطية & نظم الرقابة على المشرورع & المنخفضة \\
\hline 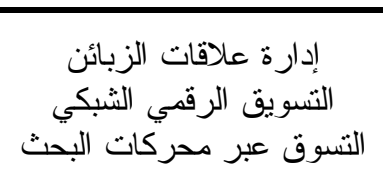 & نظم التصنيع بمساعدة الحاسوب نظم الجودة & قاعدة بيانات البحث و التبر التطوير & 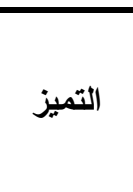 \\
\hline
\end{tabular}

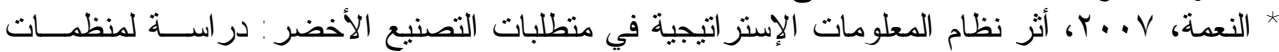

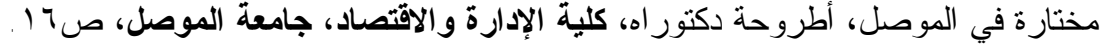

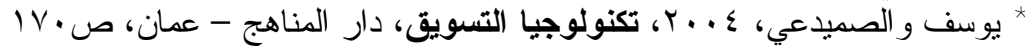

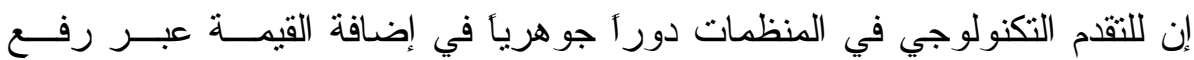

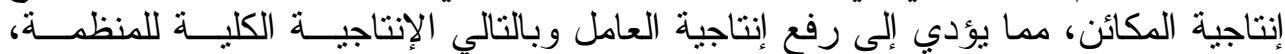

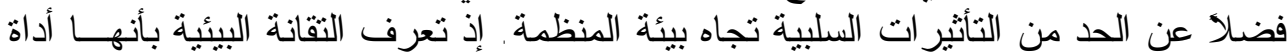

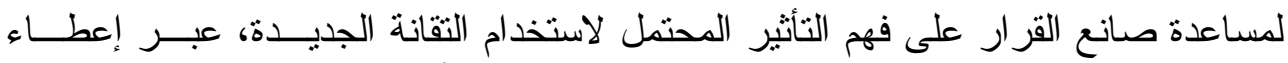

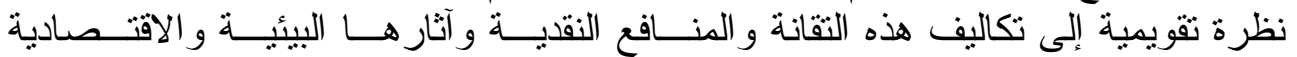
و الاجتماعية. كما يكمن هدف تقويم هذه التقانة في المساعدة على القيام باختبار ات قائمسـة 


\section{[190] الجبوري[20}

على أساس علمي بين الثقانات التي تكون منسجمة مع الأداء البيئي الأفضل . فمن خـــلال

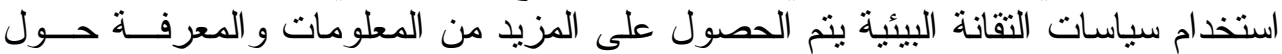

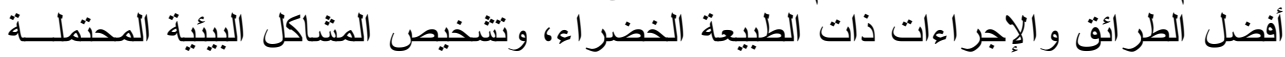

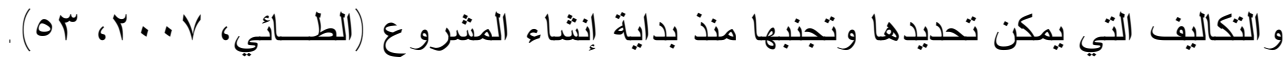

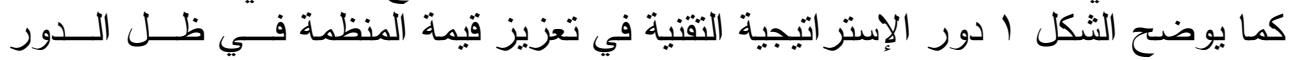
البئُي

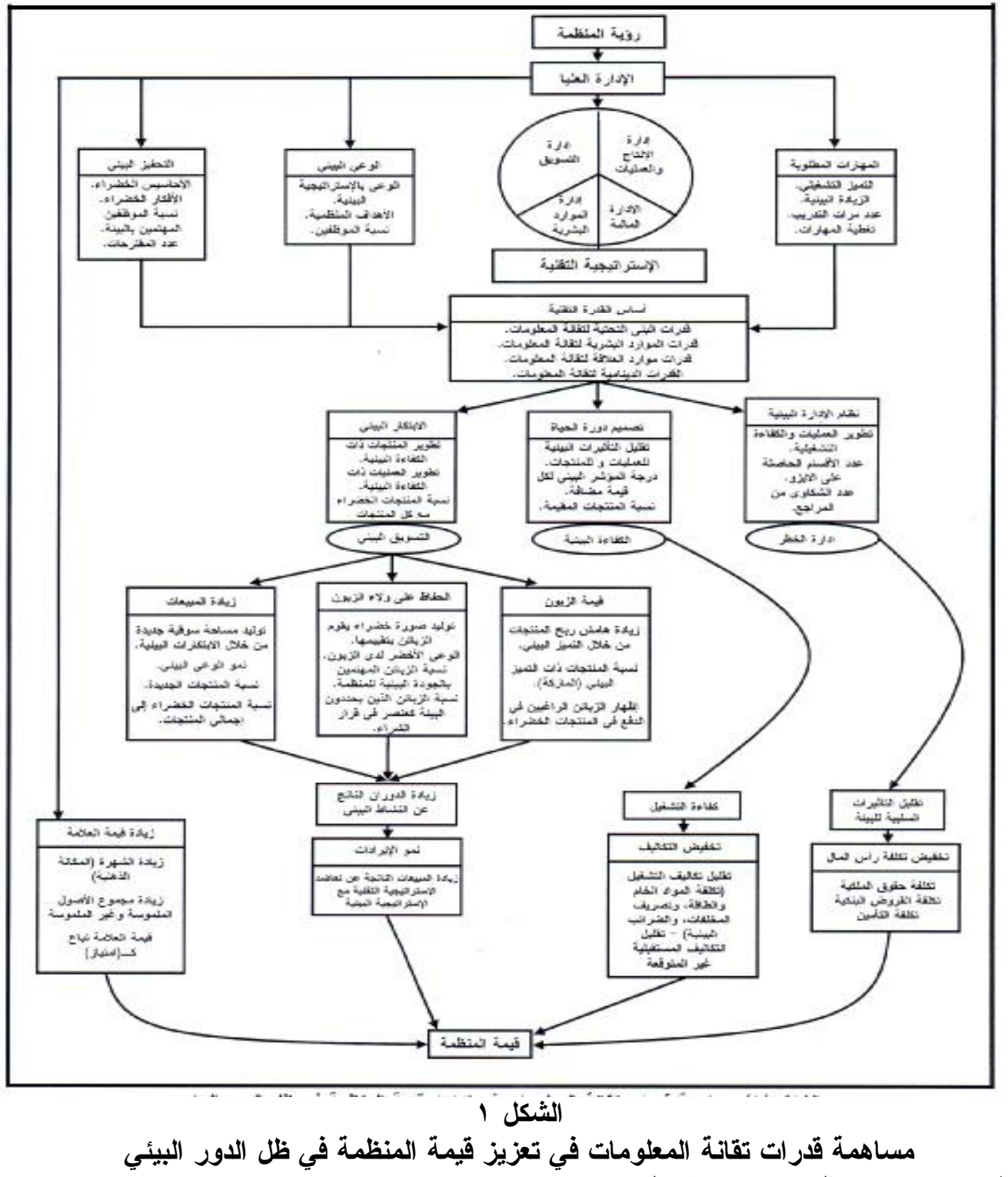

المصدر: بتصرف الباحث بالاعتماد على فيلى

Hockerts, K. (2001), "Corporate Sustainability Management - Towards Controlling Corporate Ecological and Social Sustainability ", In: Proceedings of Greening of Industry Network Conference, 21 - 24 Jan, Bangkok, P10. 


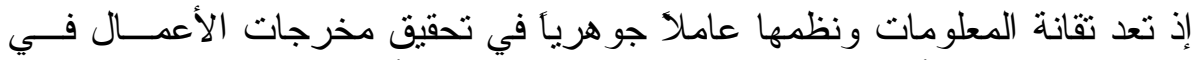

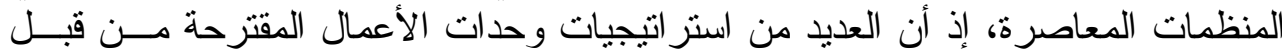
(Porter)

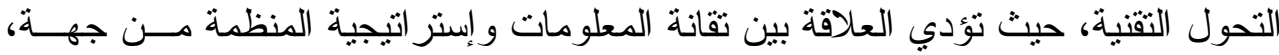

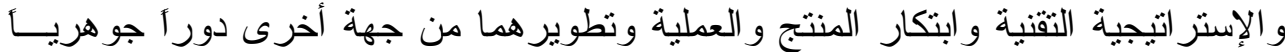

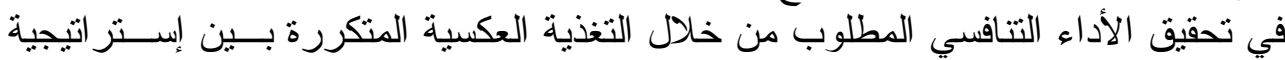

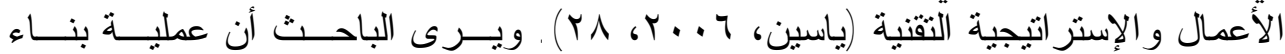

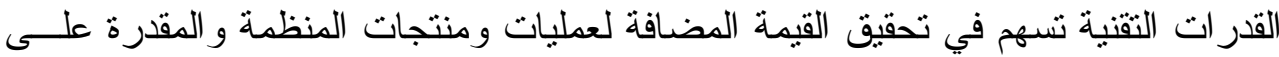
تجنب المخاطر المختلفة و إدارة الأزمات في بيئة الأعمال .

\section{r. قدرات تقانة المعلومات: المفهوم والتطور والأثواع}

Information Technology Capabilities: The Concept \& Development \& Types

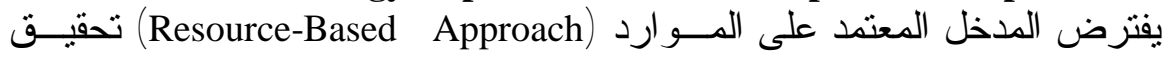

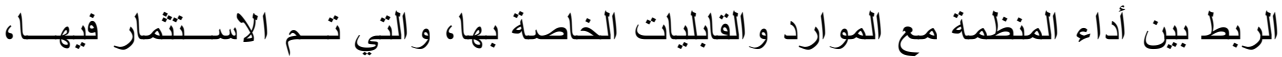

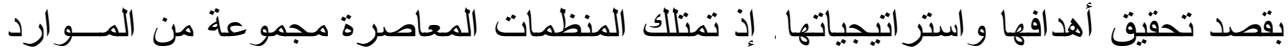

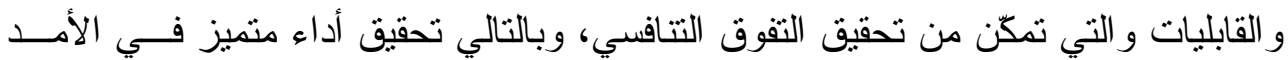

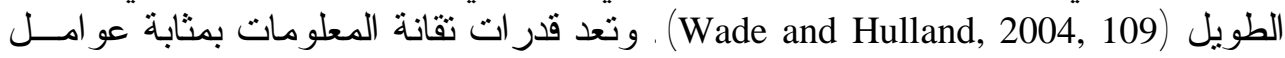

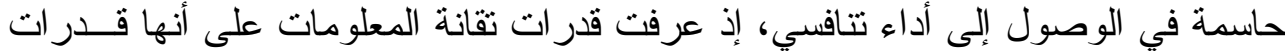

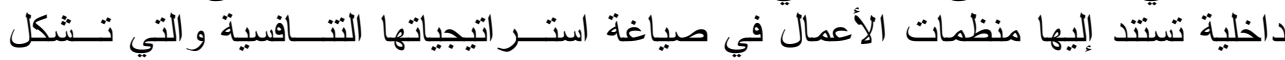

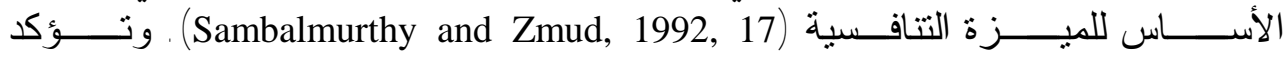
(Bharadwaj, et. al, 2002, 4)

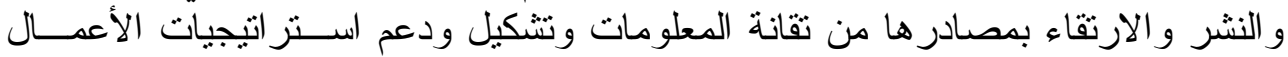

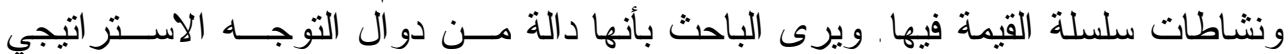

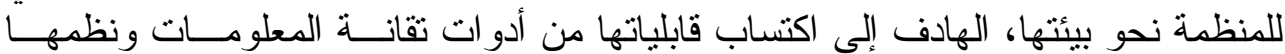

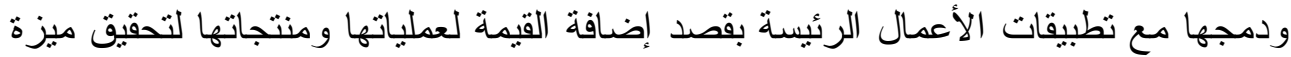

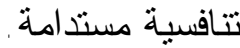

ويلاحظ الباحث أن التطور الحاصل في قدر ات ثقانة المعلومات لمنظمات الأعمــال

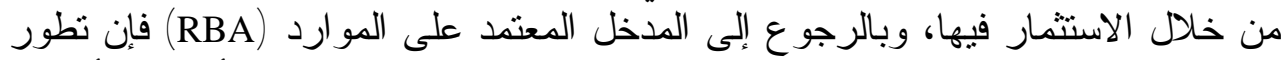

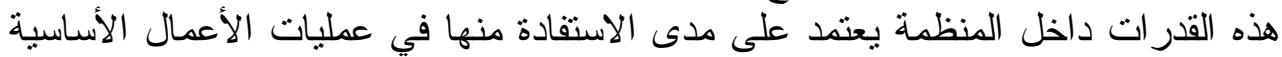

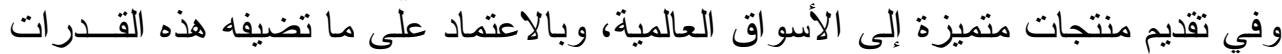

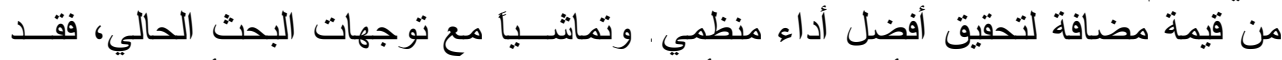

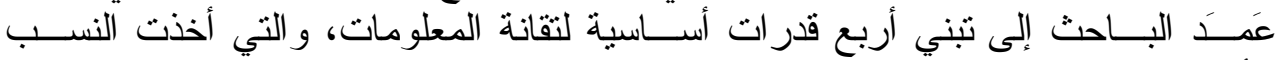
الأعلى من اتفــاق البــاحثين (Bharadwaj, et. al, 1999)، و (Bhatt and Grovre, 2005)؛

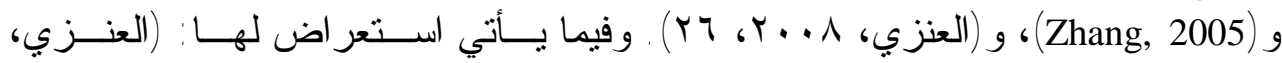

$\left(r V_{6}, r_{1} . .1\right.$

أولاً - قدرات البنى التحتية لتقانة المعلومات

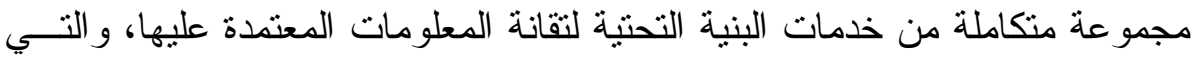
تكون متاحة لدعم التطبيقات الحالية و المبادرات الجديدة في المنظمة ـ إن الاستثمار في هذه 
[19v[الجبوري

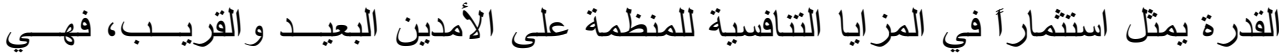

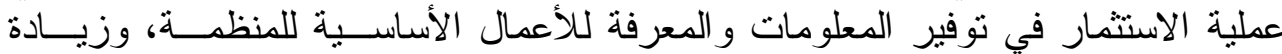

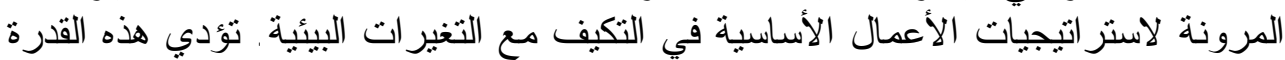

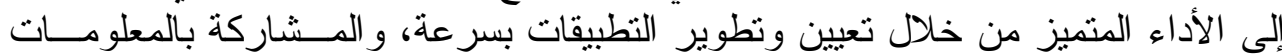

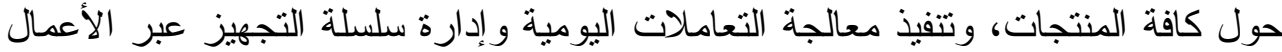

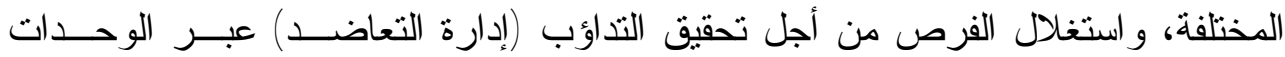

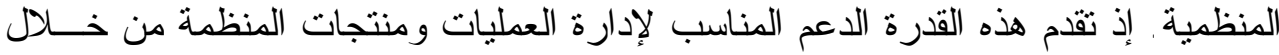

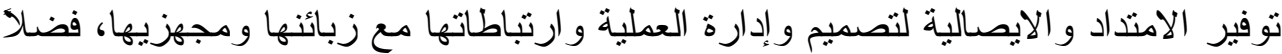

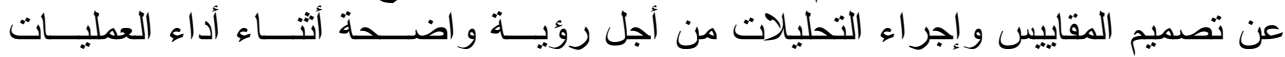

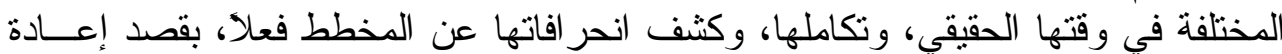
تصميم ونتكيل استجابة أكبر و وأسر ع للعمليات.

ثانياً - قدرات الموارد البشرية لتقانة المعلومات

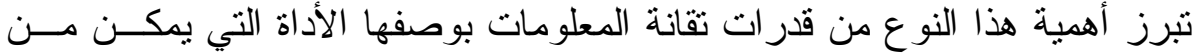

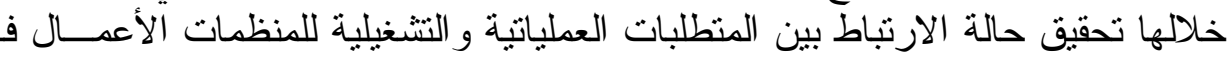

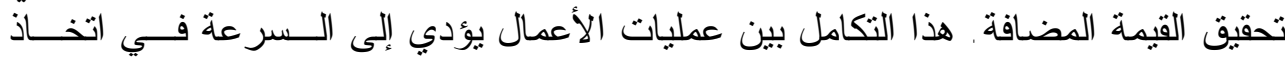

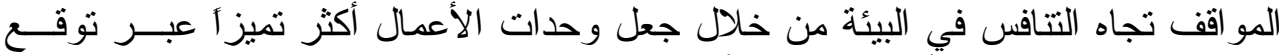

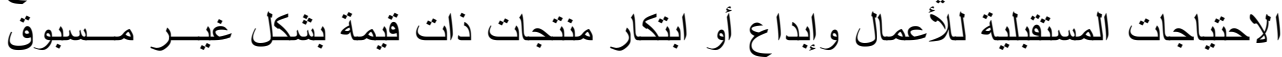

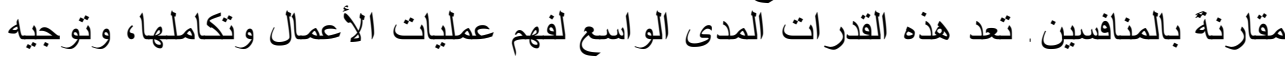

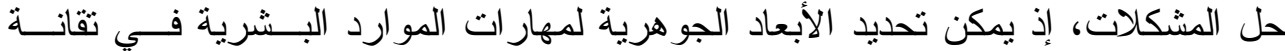

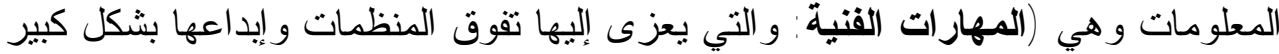

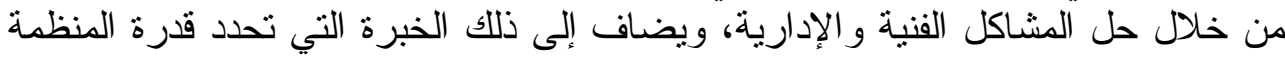

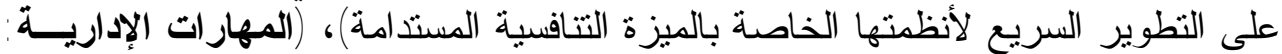

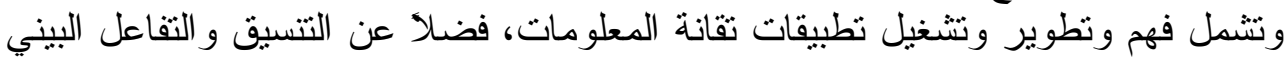

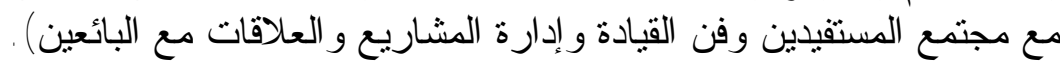

ثالثاً - قدرات موارد العلاقة لتقانة المعلومات

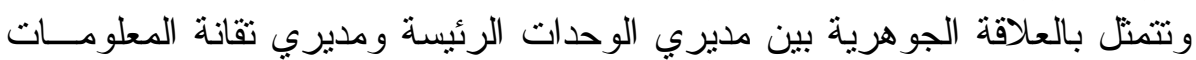

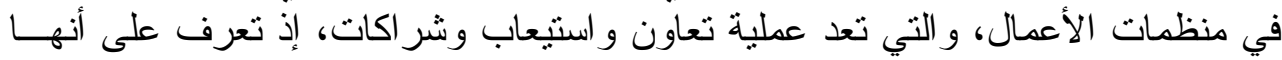

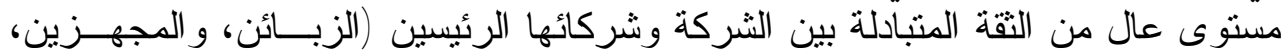

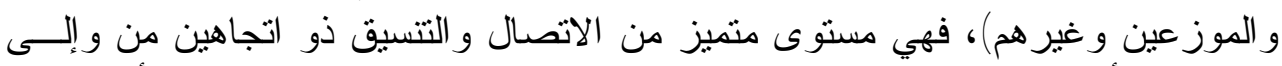

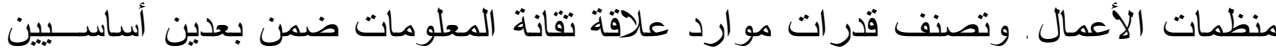

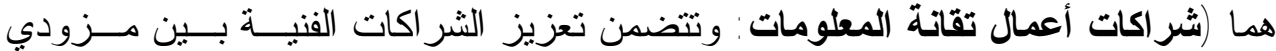

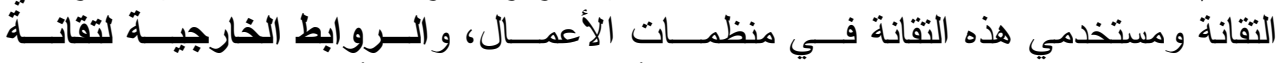

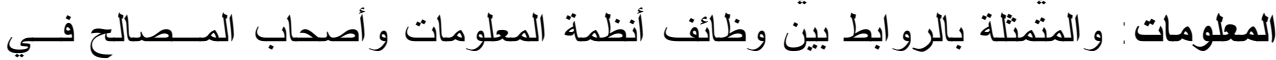

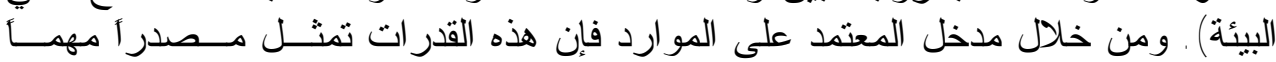

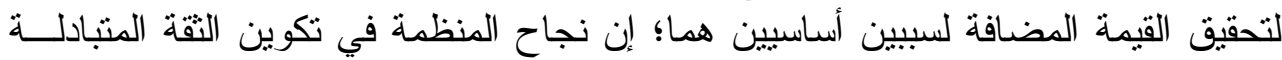

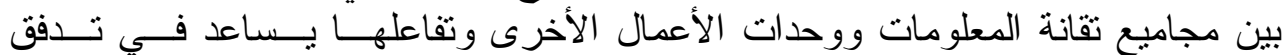
المعلومات ونشر المعرفة في إنحاء المنظمة. و إن أحد الأجزاء المقومة الرئيـسـة للبنـى اعلى 
التحتية لموارد العلاقة لتقانة المعلومات هي الثقة التي تتطور بين مجاميع تقانة المعلومات

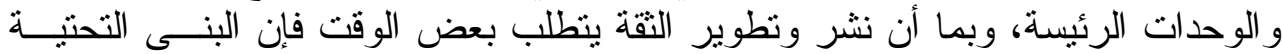

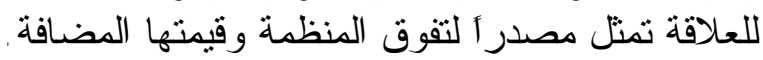

رابعاً - القدرات الدينامية لتقانة المعلومات

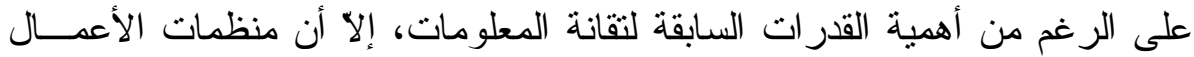

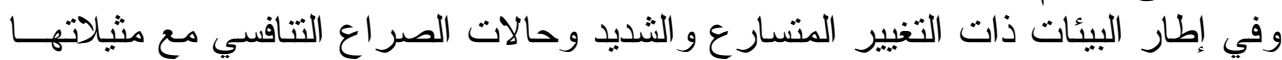

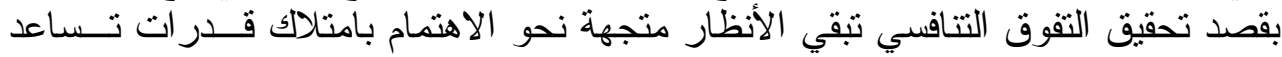

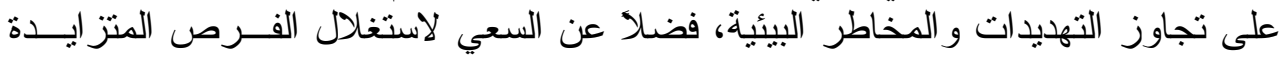

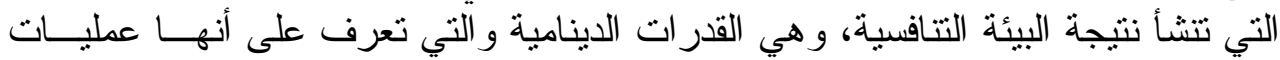

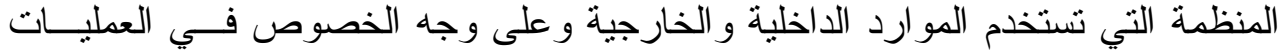

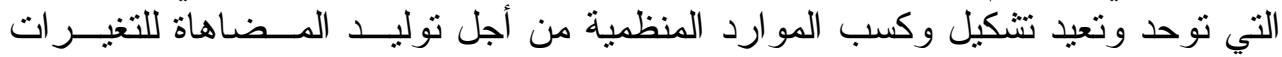

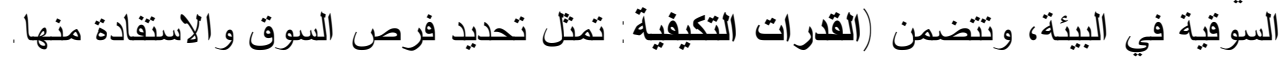

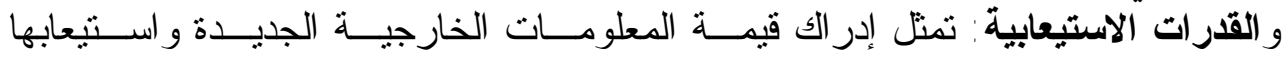

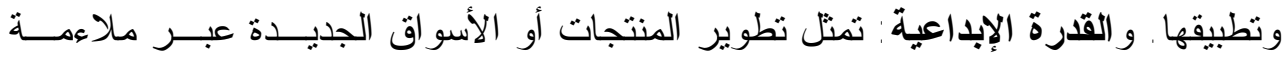

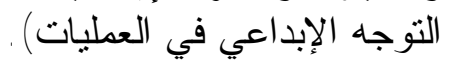

Performance \& Environmental Performance الأداء والأداء البيئي

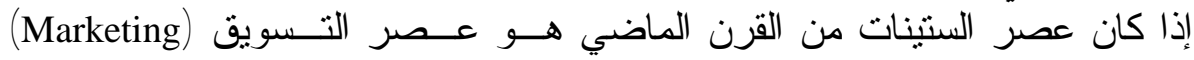

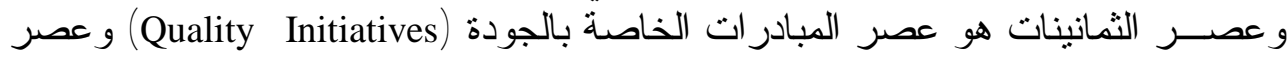

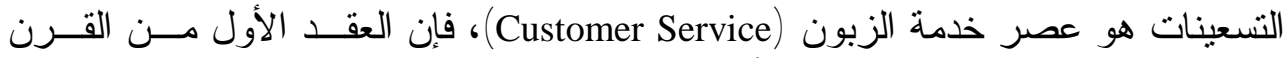

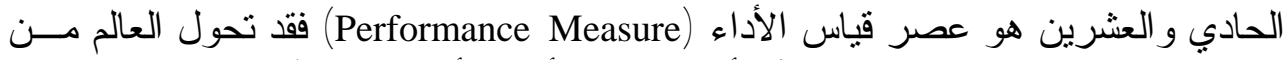

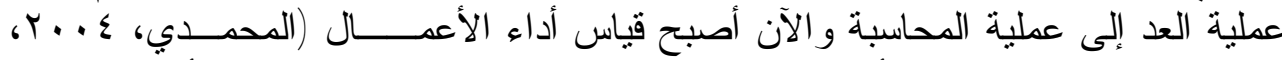

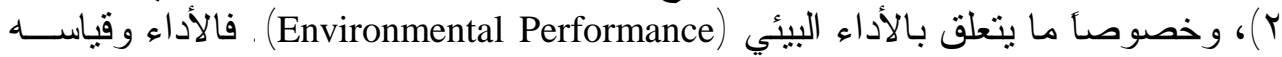

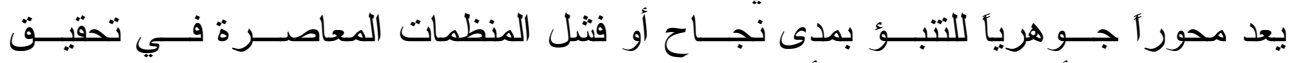
استر اتيجياتها و أهدافها في بيئة الأعمال.

The Concept and Measurement المفهوم و القياس

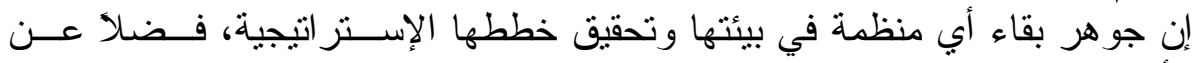

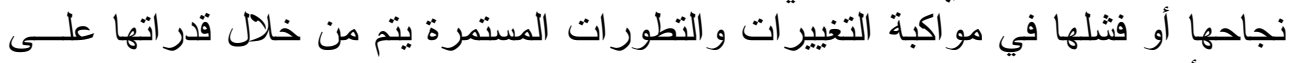

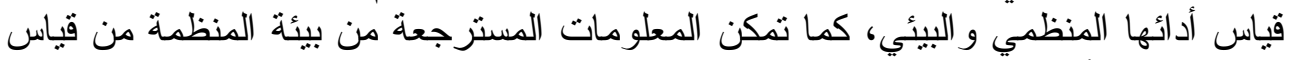

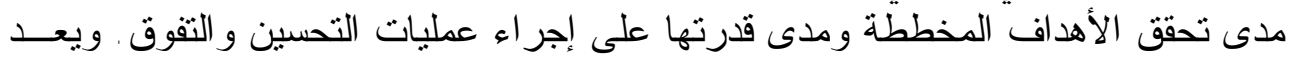

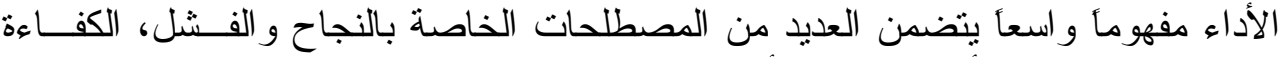

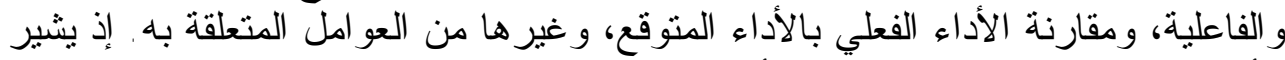

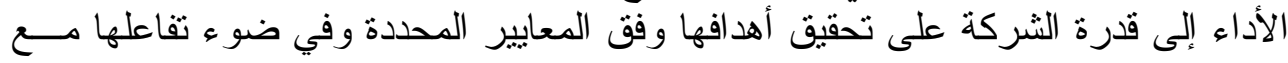

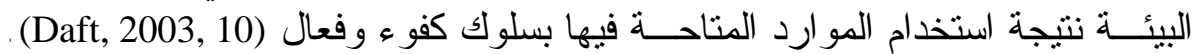

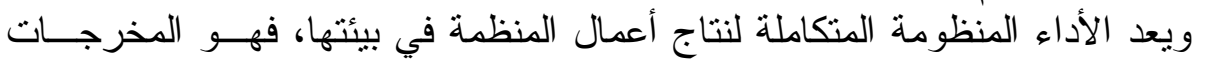

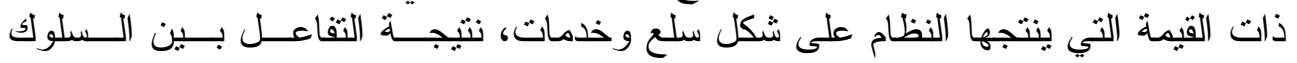
و التصرف و الإنجاز ، فهي انعكاس لكيفية استخدام المنظمة لمو اردها واستخلالها بالطريقـــة 
[الجبوري[199]

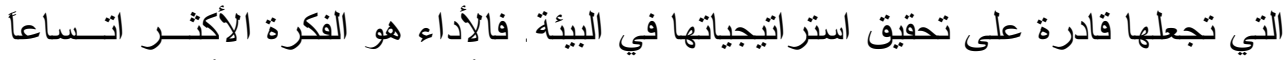

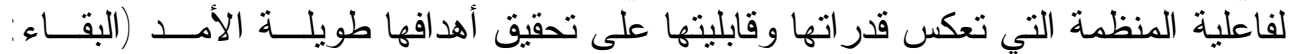

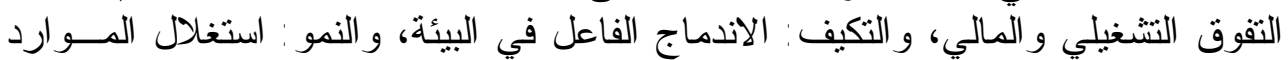

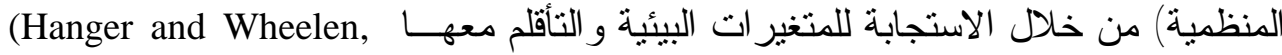
.1998, 231)

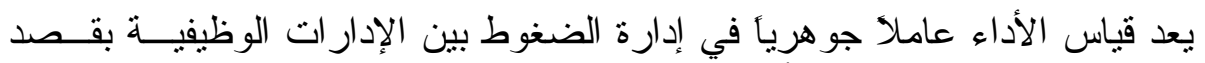

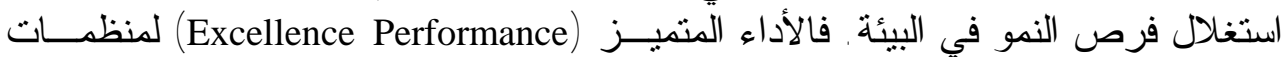

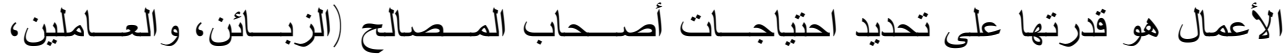

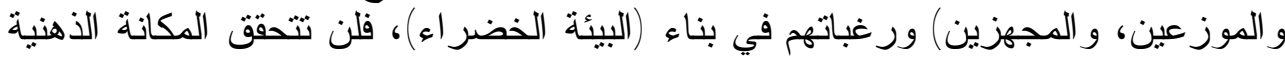

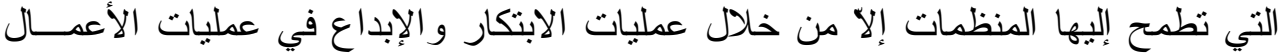

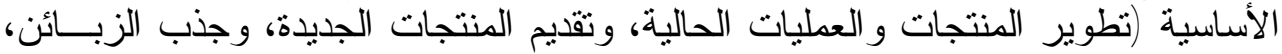

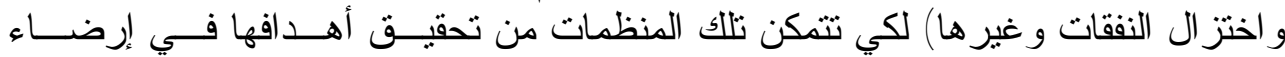

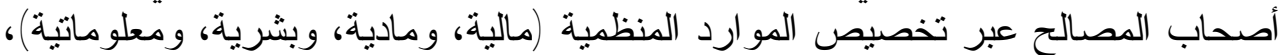

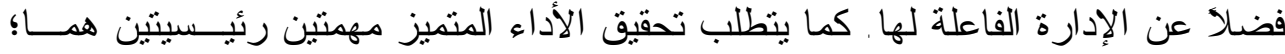

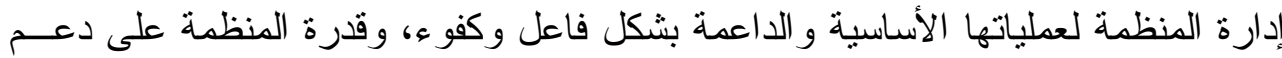

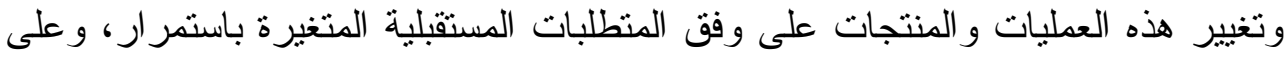
وفق إستر اتيجية المنظمة (Kotler, 2000, 41).

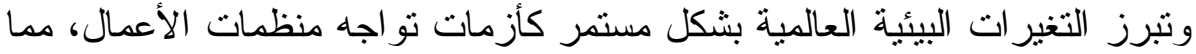

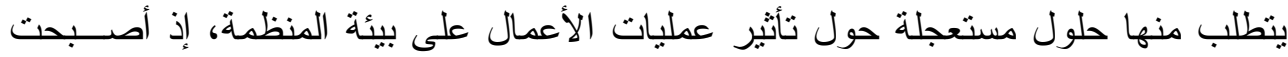

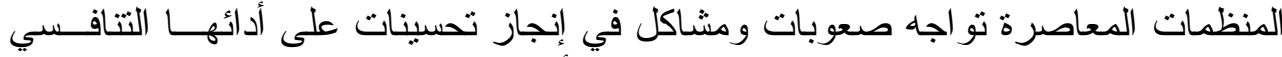

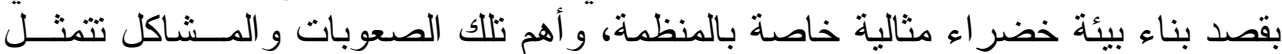

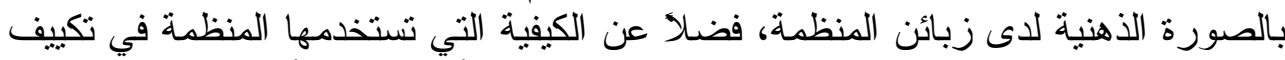

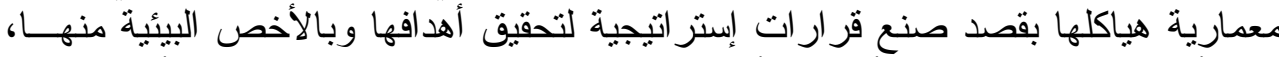

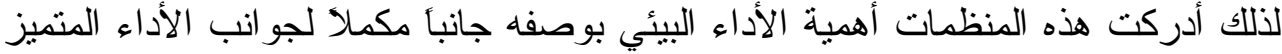

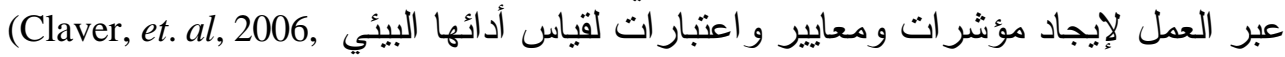

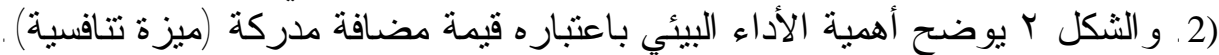




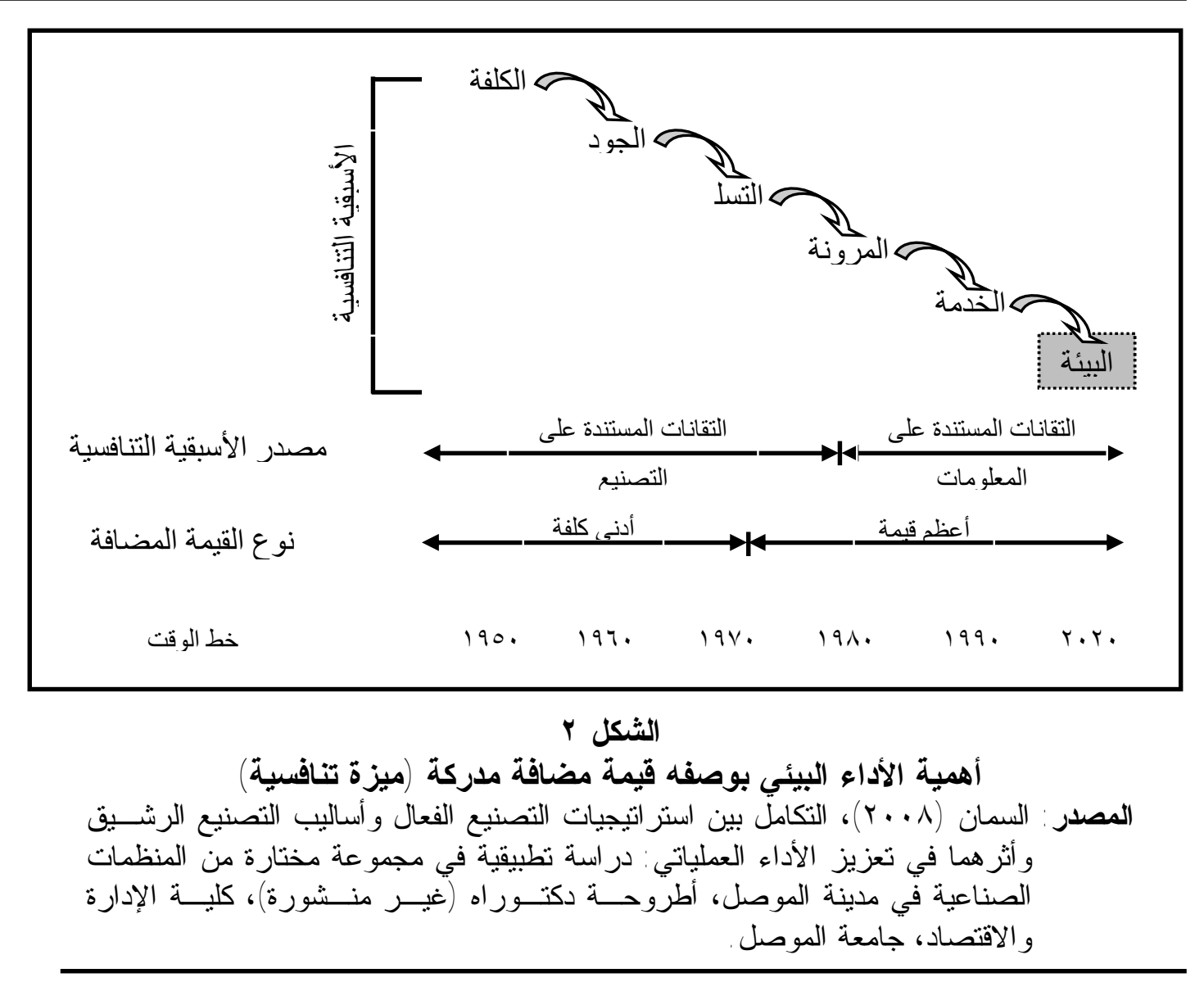

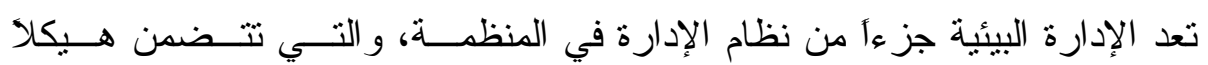

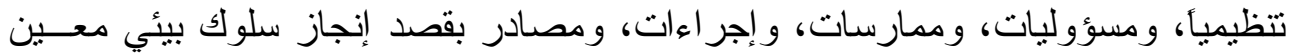

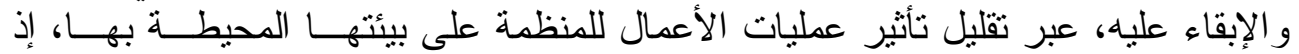

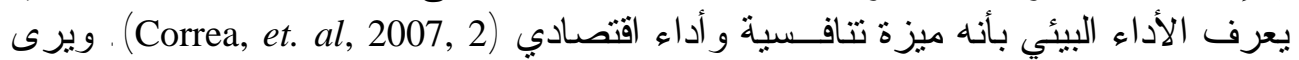
(Perotto, et. al, 2007, 4) يخص الجو انب البيئية مثلا (السياسة البيئية، و الأهداف البيئية، و الخطط البيئية) و غير ها.

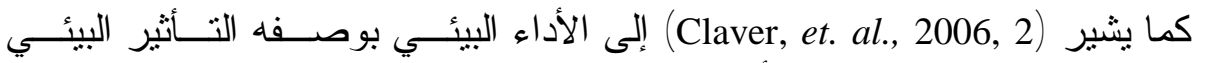

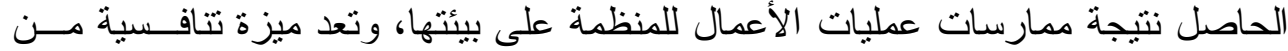

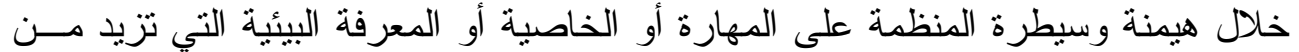

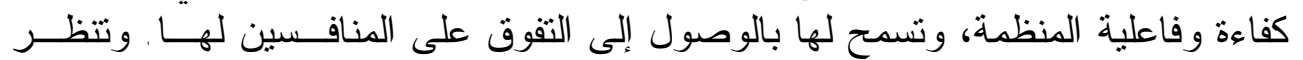

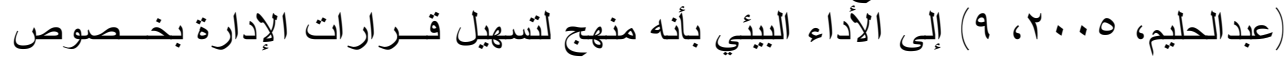

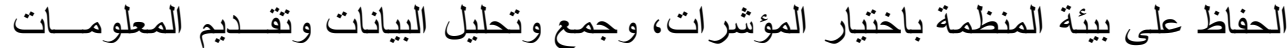

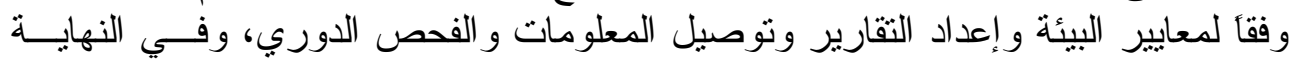
تطوير هذا المنهج و الذي يساعد على تعزيز المكانة الذهنية لدى الزبائن تجاه المنظمة ولئ 


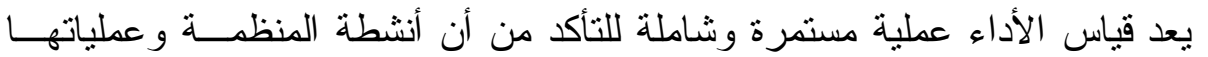

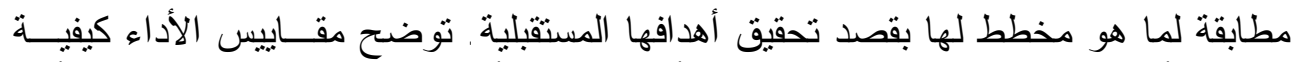

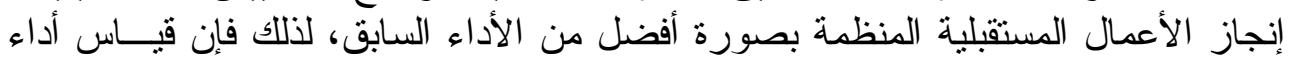

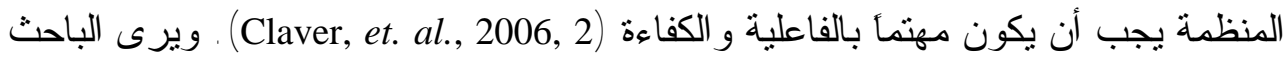

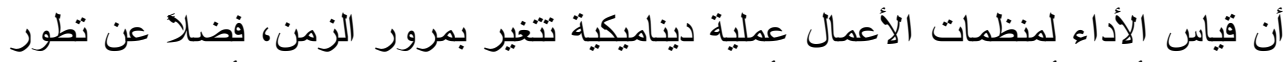

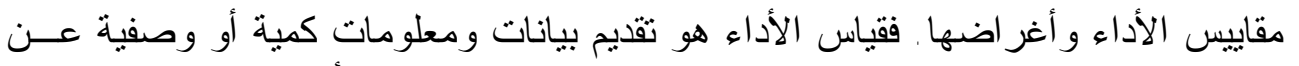

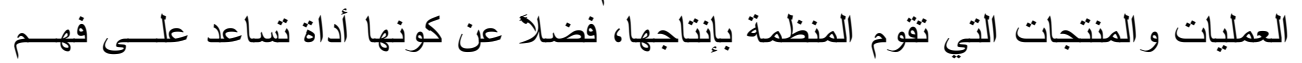
و إدارة وتحسين ما تعملة المنظمة.

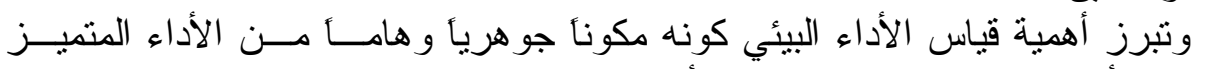

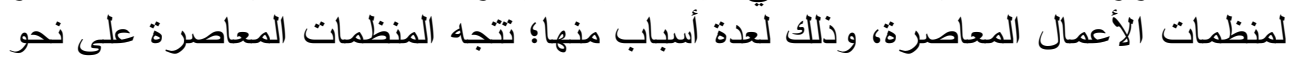

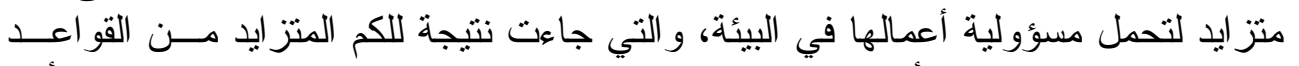

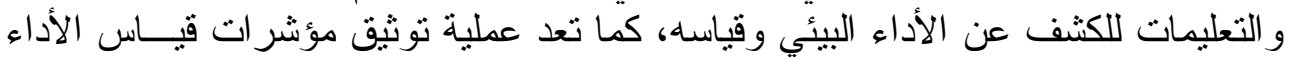

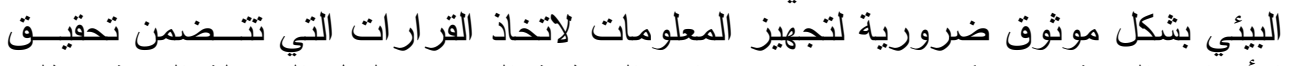

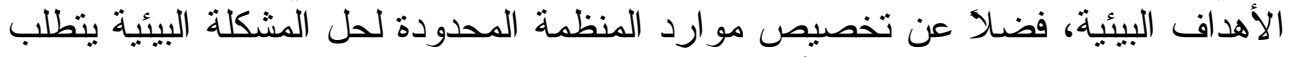

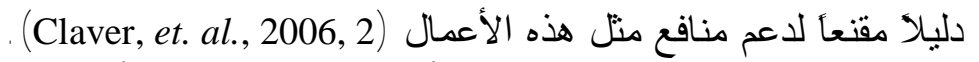

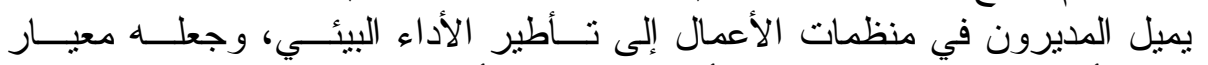

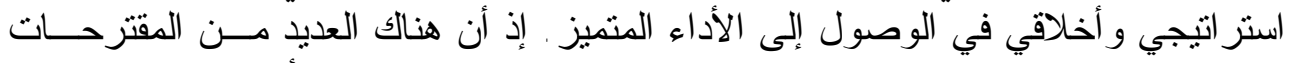

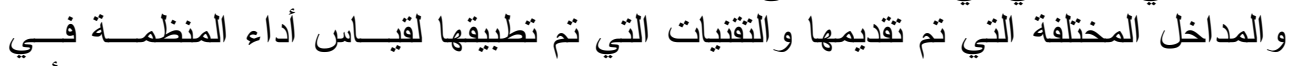

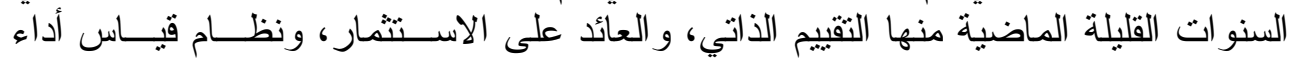

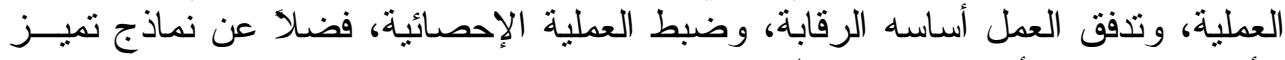

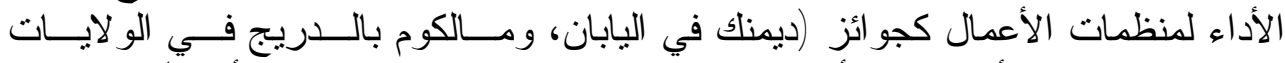

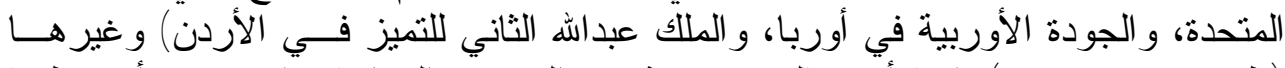

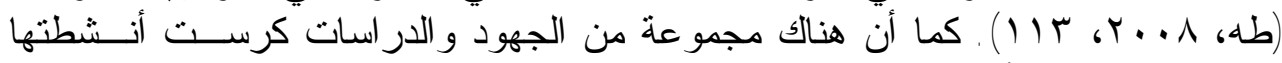

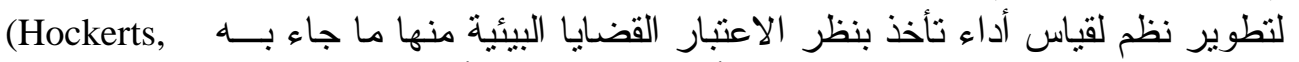

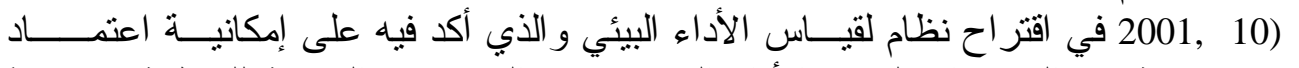

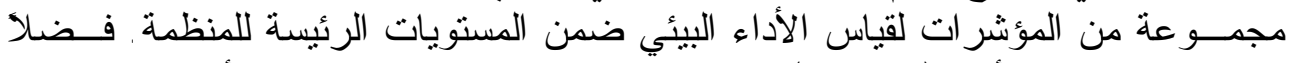

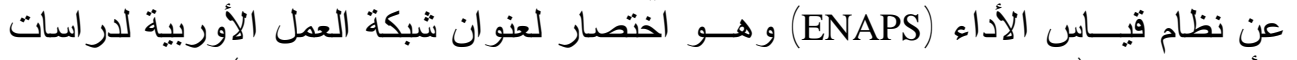

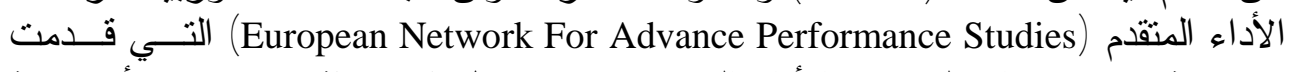

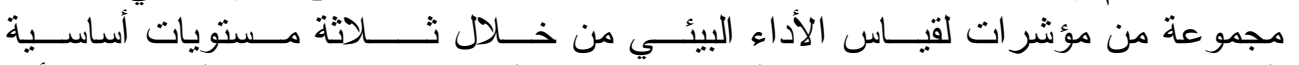

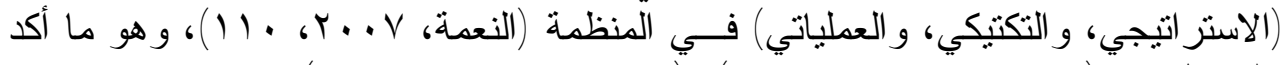

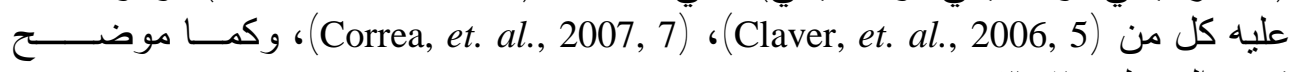
فـي الجدولين r، r r. 


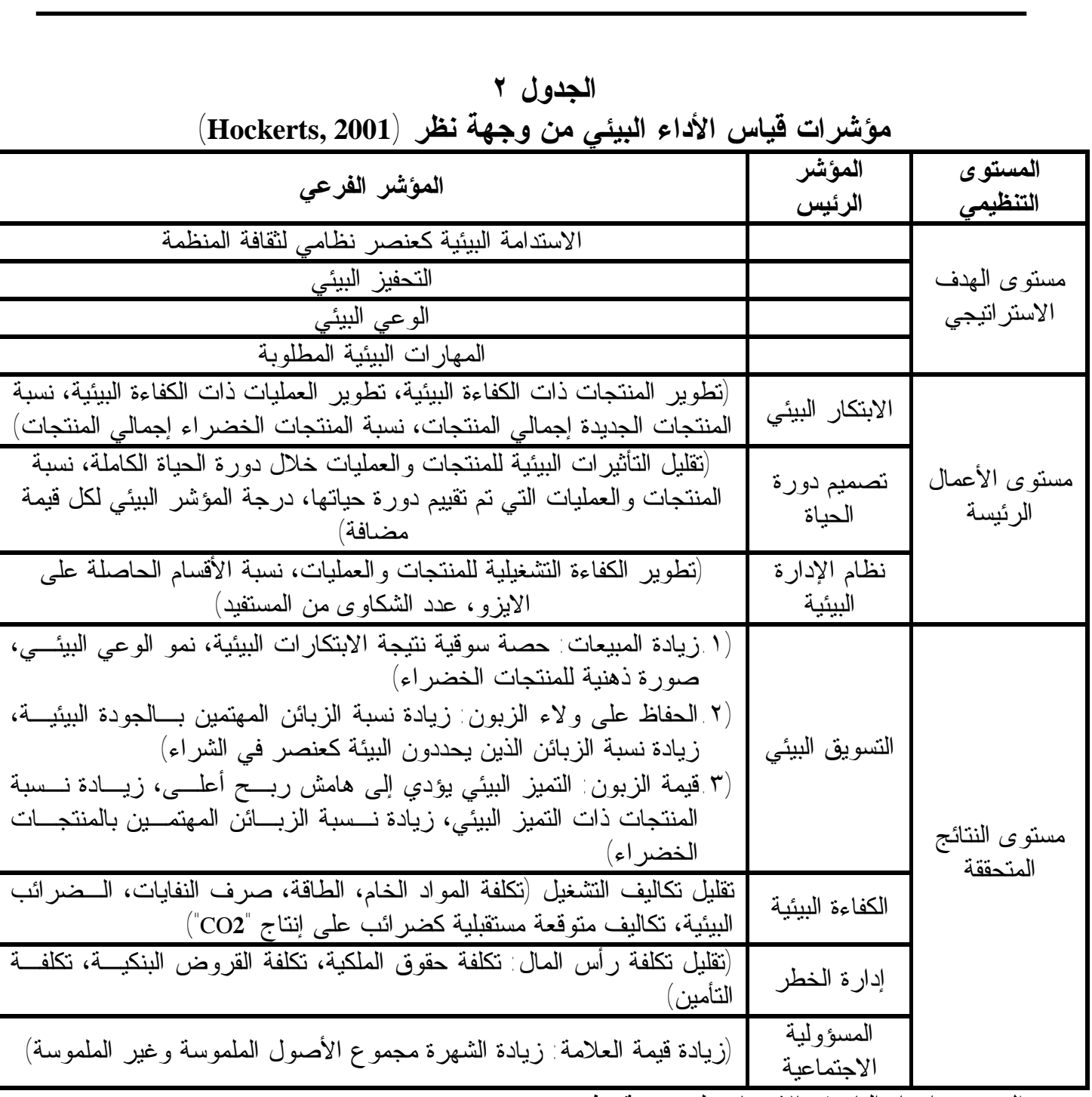

Hockerts, K. (2001) "Corporate Sustainability Management - Towards Controlling Corporate Ecological and Social Sustainability", In : Proceedings of Greening of Industry Network Conference, 21-24. Bangkok, P 10. 


\section{الجبوري[r.r.}

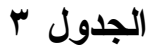

مؤشرات قياس الأداء البيئي من وجهة (ENAPS)

\begin{tabular}{|c|c|c|}
\hline شرح المؤشر & نوع المؤشر & التنظيمي المستوى \\
\hline 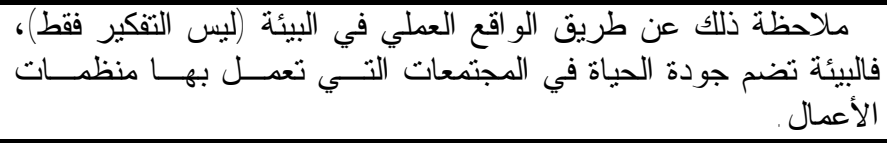 & وجود إستر اتئية أونية أو & \multirow{4}{*}{ الاستر اتيجي } \\
\hline 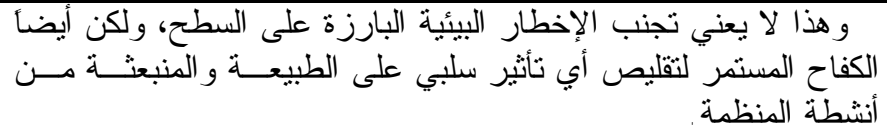 & الاهتمام البيئي الحقيقي & \\
\hline 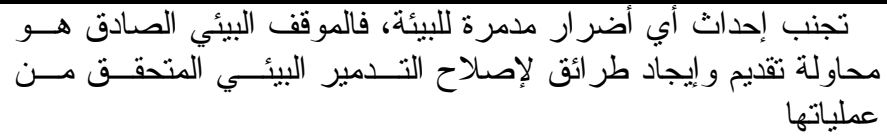 & الإسهامات في تحسين & \\
\hline تتضمن هياكل ومسؤوليات و إجر اءات بيئية معتمدة في المنظمة & وجود إدارة بيئية & \\
\hline غير القابلة للتعويض النفايات و التلوث المترتبة على استعمال الطاقة و المـــوارد & الخيار ات الإستر اتيجية الخية & \multirow{4}{*}{ التكتيكي } \\
\hline غير القابلة للتعويض النفايات و التلوث المنرتبة على التيات التحويل الخاصـة بالمنظمة الطاقة و المــو ارد & 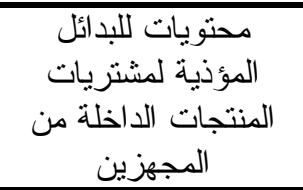 & \\
\hline 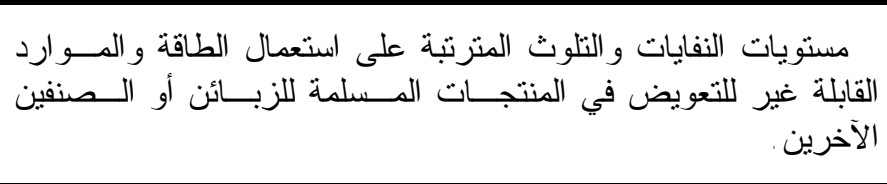 & 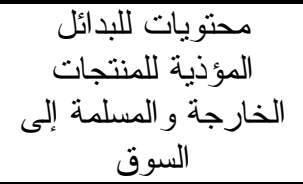 & \\
\hline و المكونات و الموارد التشجيع على إعادة الاستعمال و التدوير للمنتجات الداخلــة & لدرجة الحفاظ العام & \\
\hline 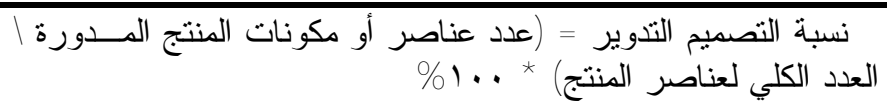 & إجر اءعات التعديل أو المنتج & \multirow{5}{*}{ العملياتي } \\
\hline 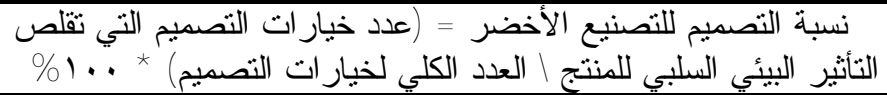 & إجر اءات التعديل أو & \\
\hline الأخضر | إجمالي المبيعات المنتج) *. .. 1\% (المبيعات منتج حصل على الملصق & عملية الأعمال للحصول التز ام الزبون & \\
\hline 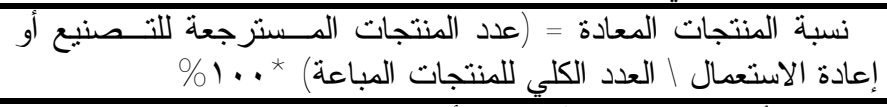 & عملية الأعمال لخدمة & \\
\hline 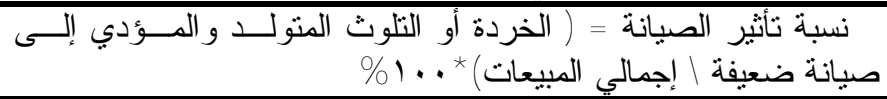 & عمليات الدعم الثانوية & \\
\hline
\end{tabular}

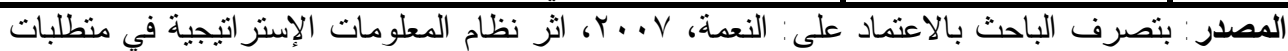

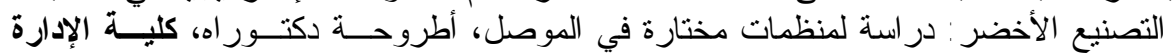


r. أنموذج ســلســلة القـيمة (Value Chain Model) كمدخل لتعزيز الأداء البيائي

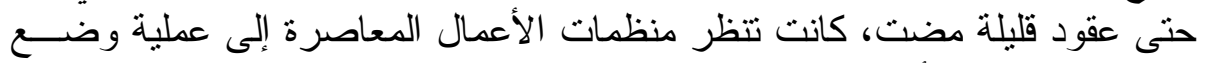

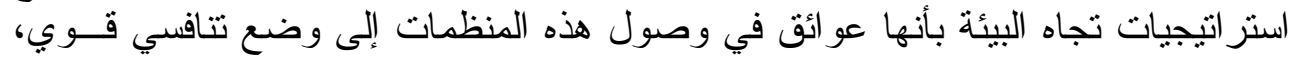

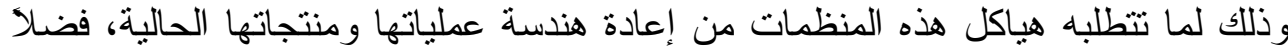

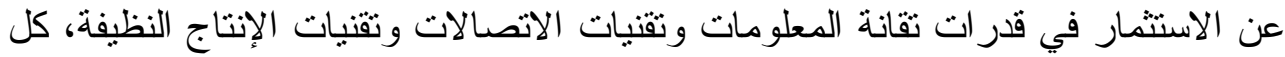

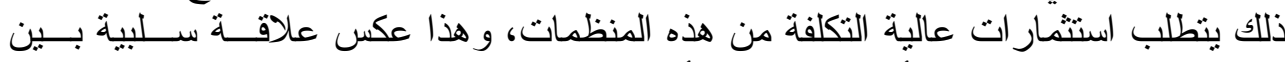

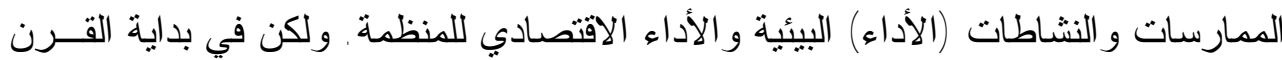

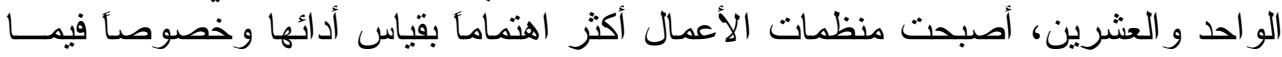

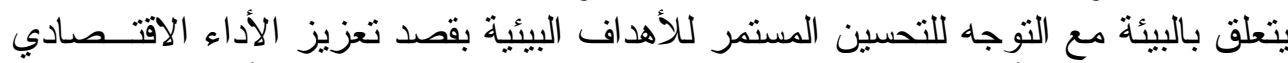

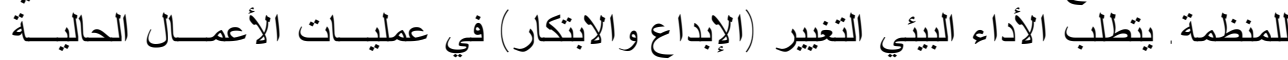

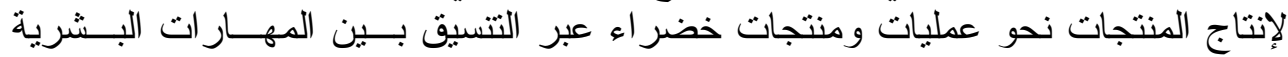

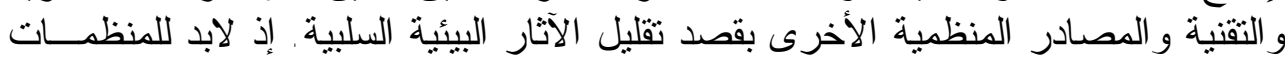

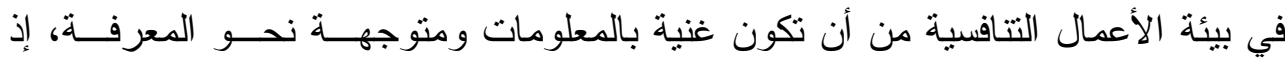

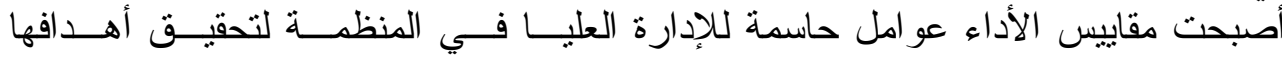

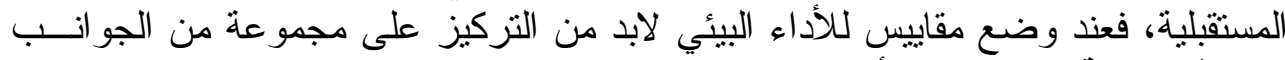

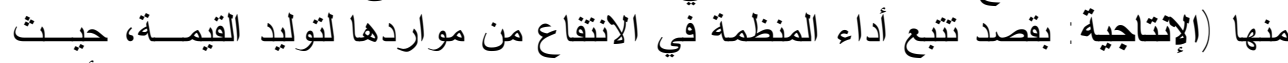

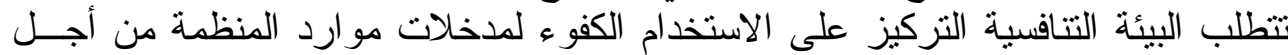

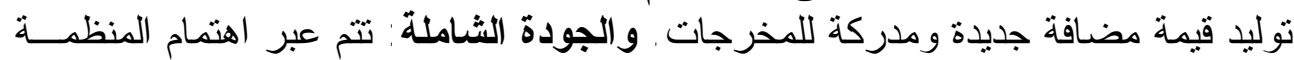

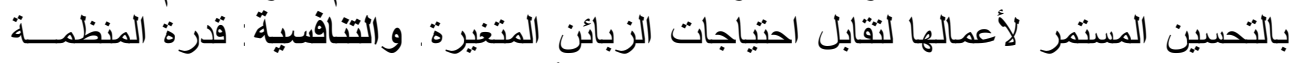

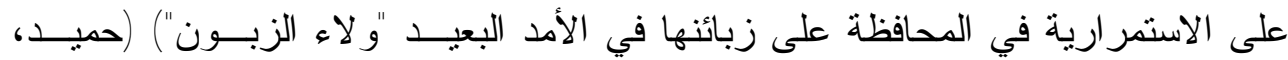

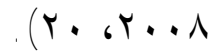

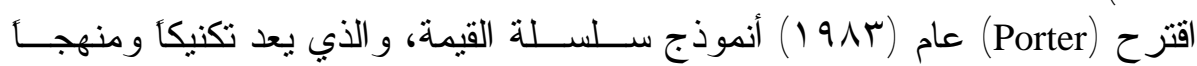

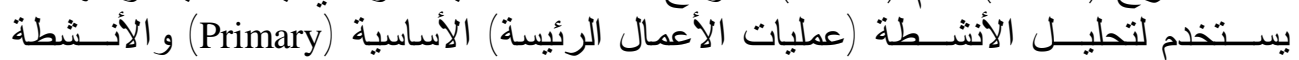

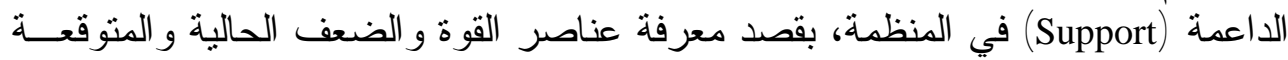

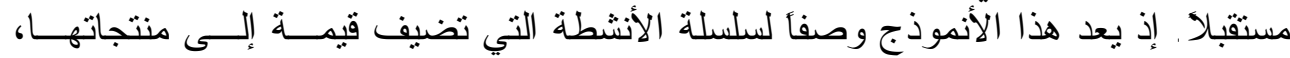

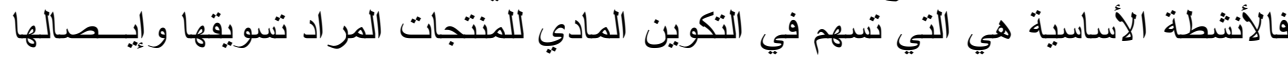

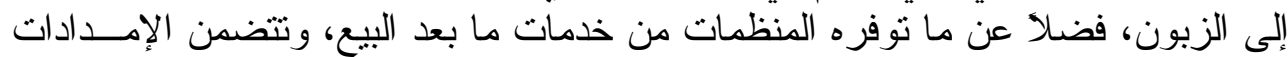

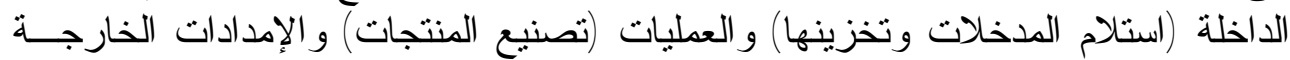

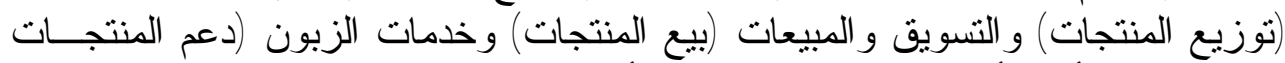

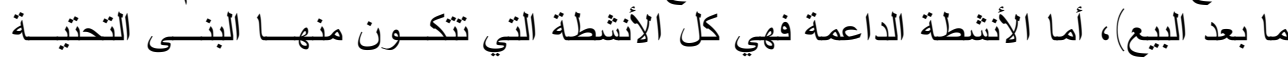

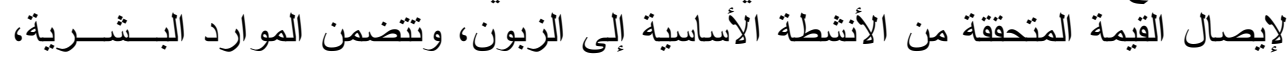

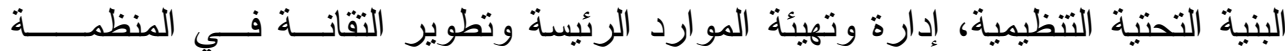

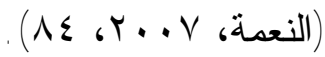

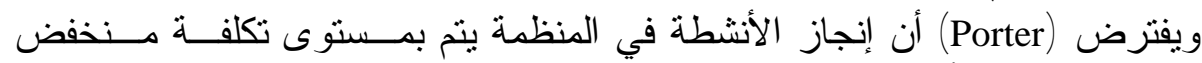

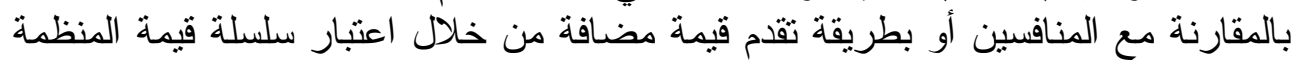

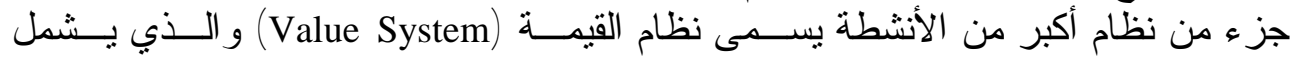

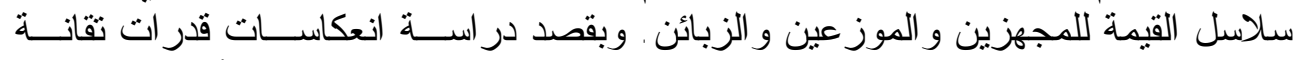

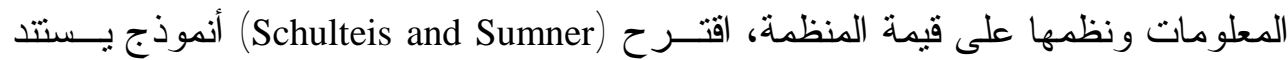

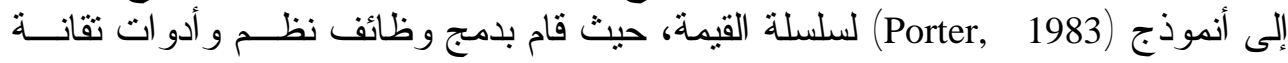




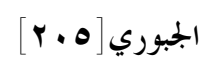

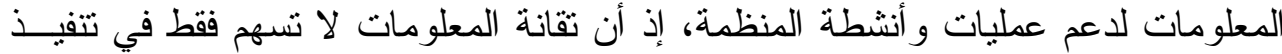

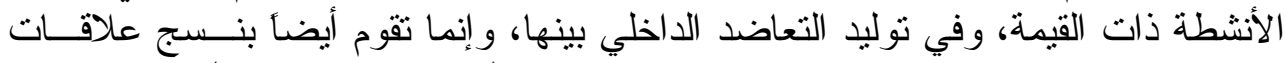

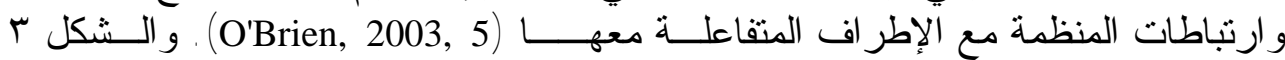
يوضح اندماج نظم وأدوات نقانة المعلومات في عمليات الأعمال على وفق النقات أنموذج سلسلة القيمة لـ (Schulteis and Sumner).

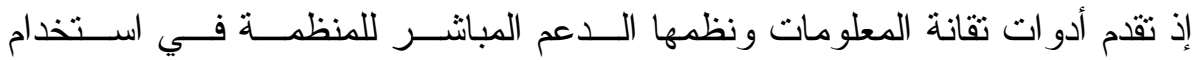

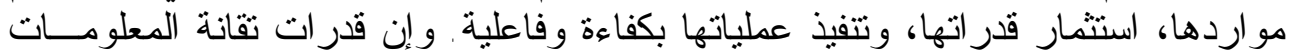

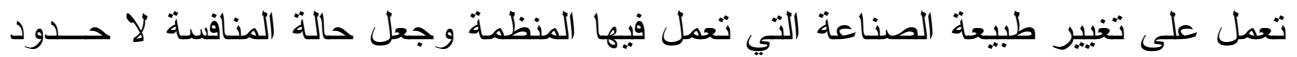

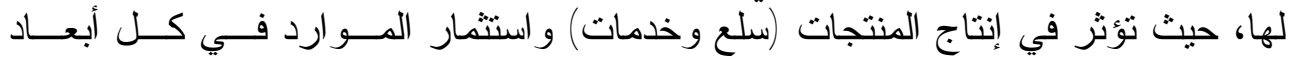

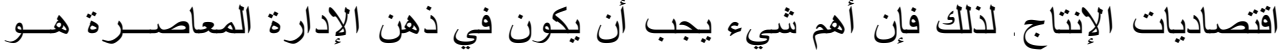

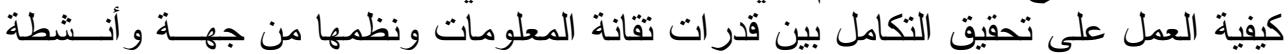

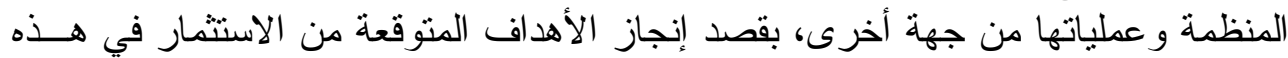

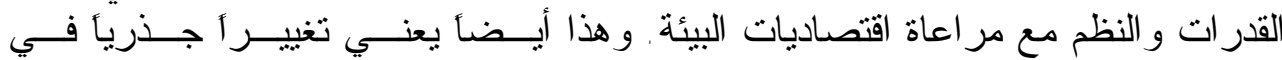

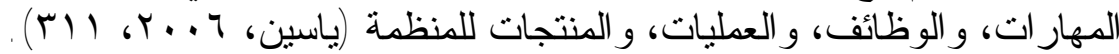

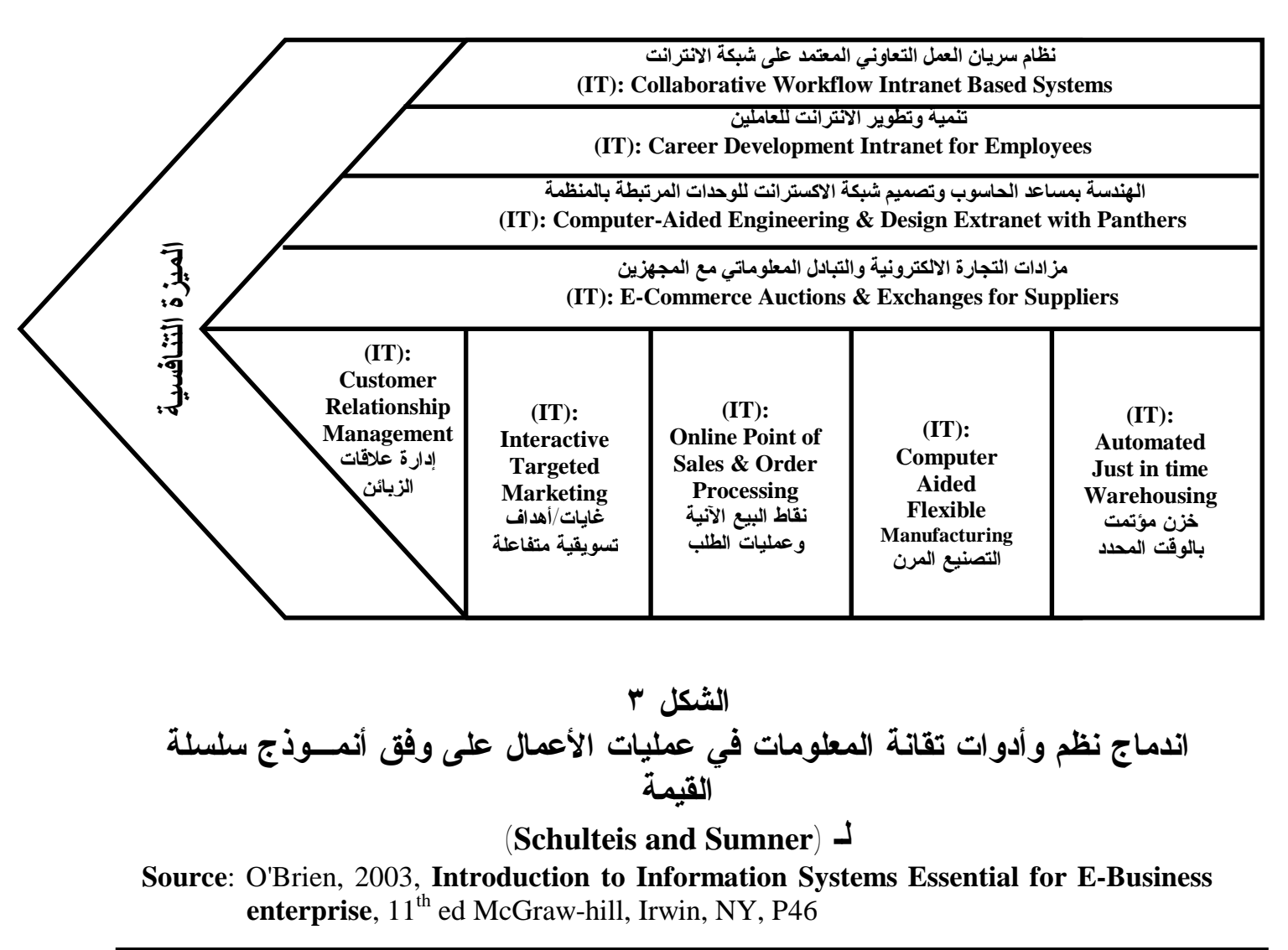

إن التركيز على استخدام مفهوم سلسلة القيمة كأسلوب لبلوغ غأية أســـقية تتافـسية

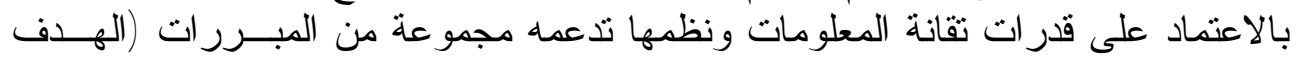


الاستر اتيجي لمنظمات الأعمال بصورة عامة هو خدمة مجتمعاتها التي تعمل فيها، وتقديم

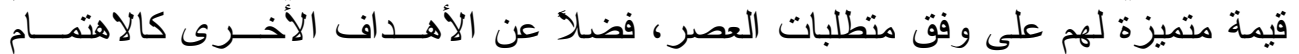

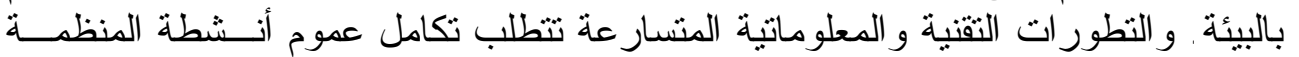

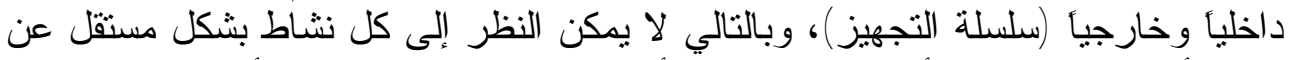

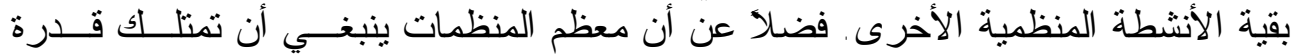

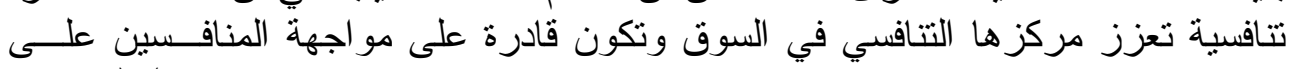

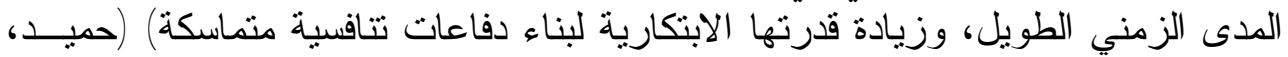

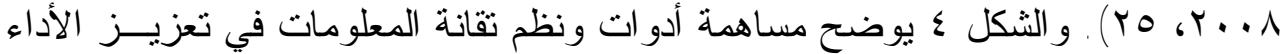

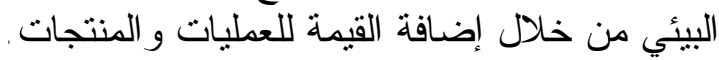

r. التعاضد بين تقانة المعلومات وعمليات الأعمال الجوهرية في المنظمات بقصد توليد من خلال الشكل السابق، نـلاحظ التعاضد بين تقانة المعلومات و عمليــات الأعمـــال

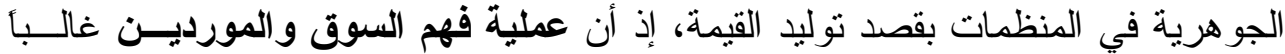

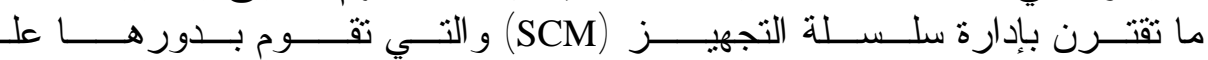

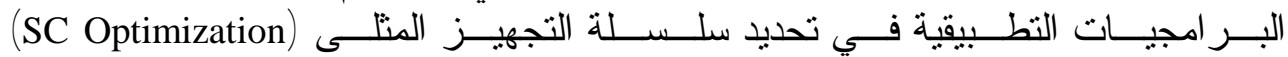

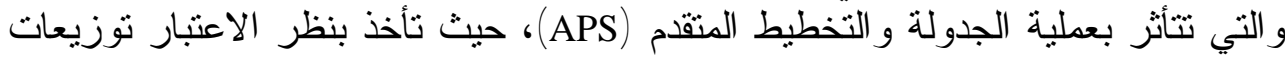

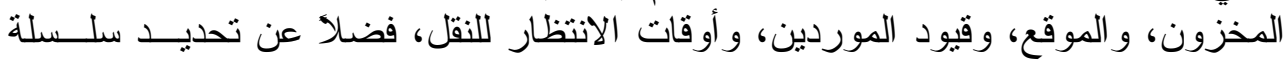

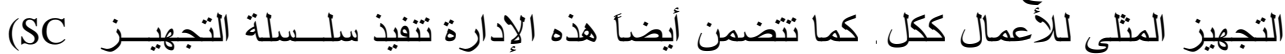

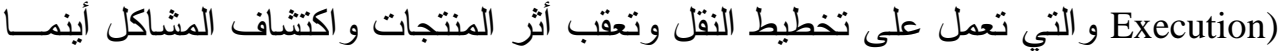

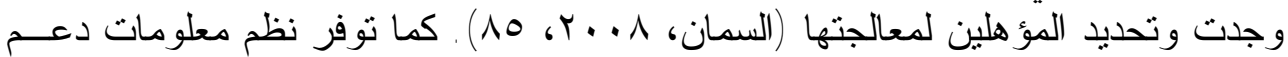

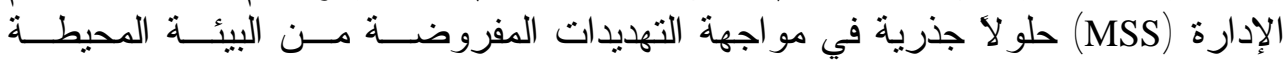

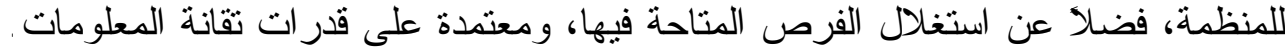

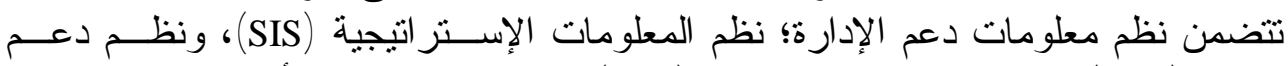

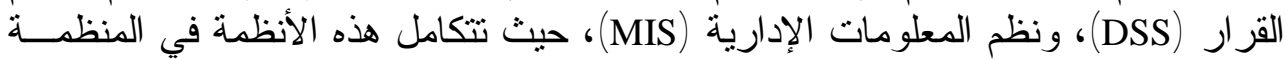

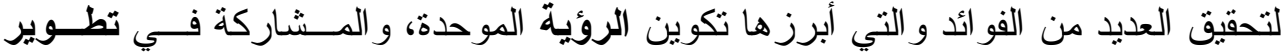

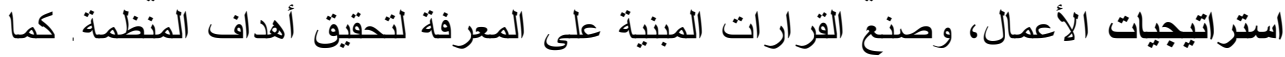

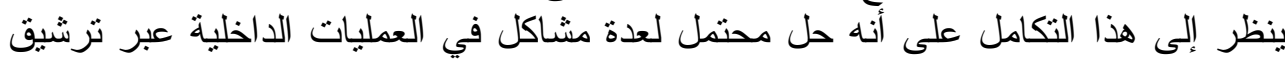

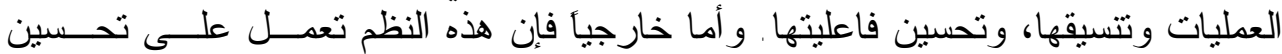

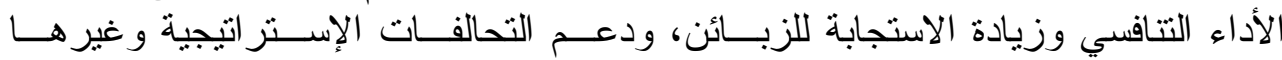

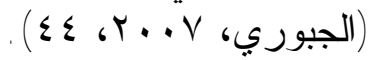

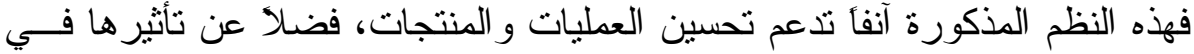

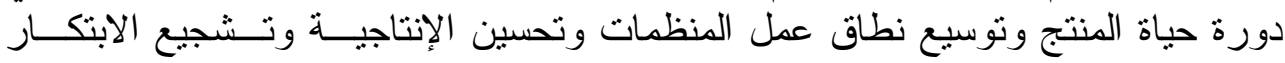

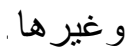

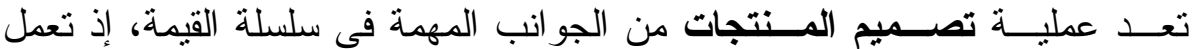

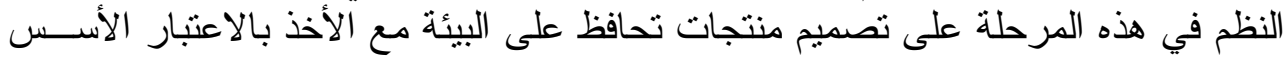

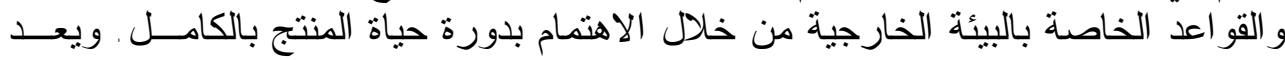

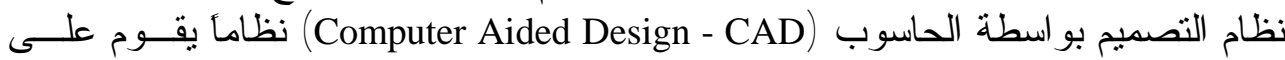

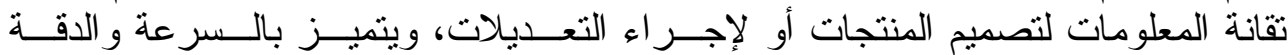


الجبوري[r.v

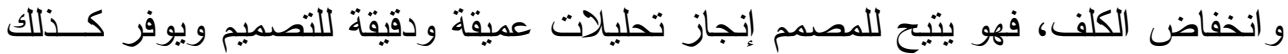

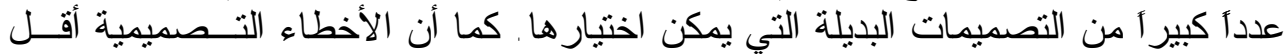

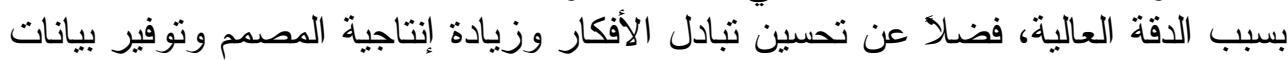

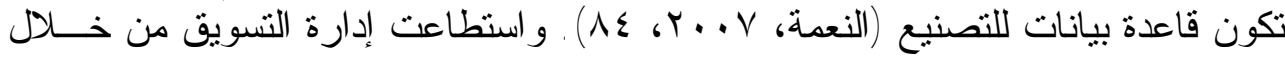

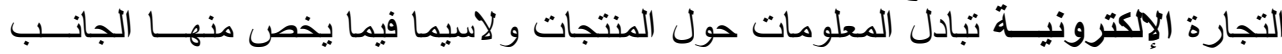

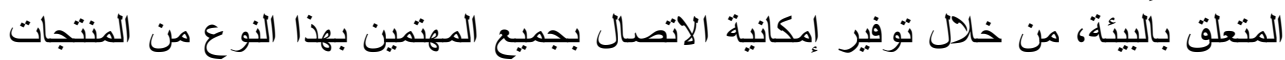

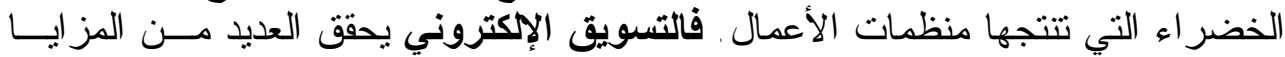

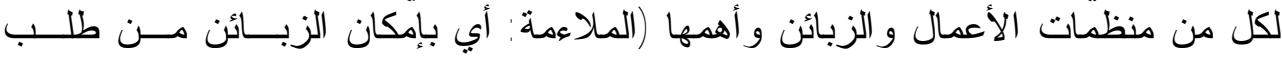

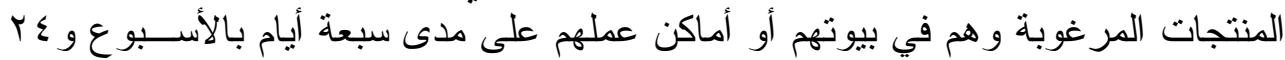

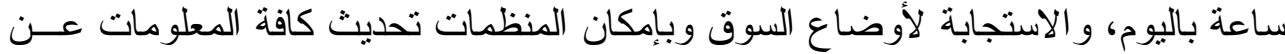

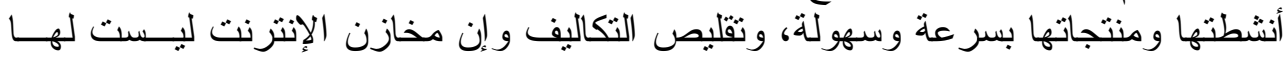

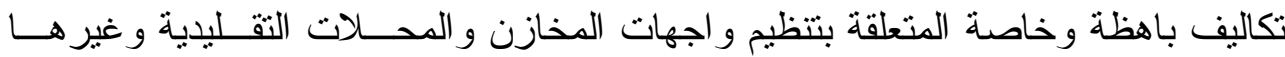

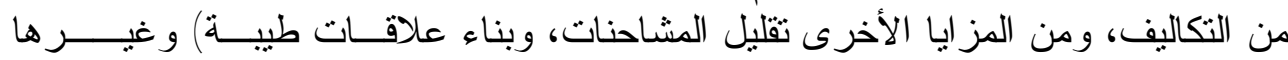

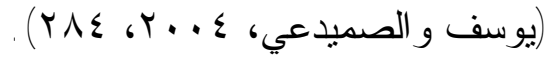

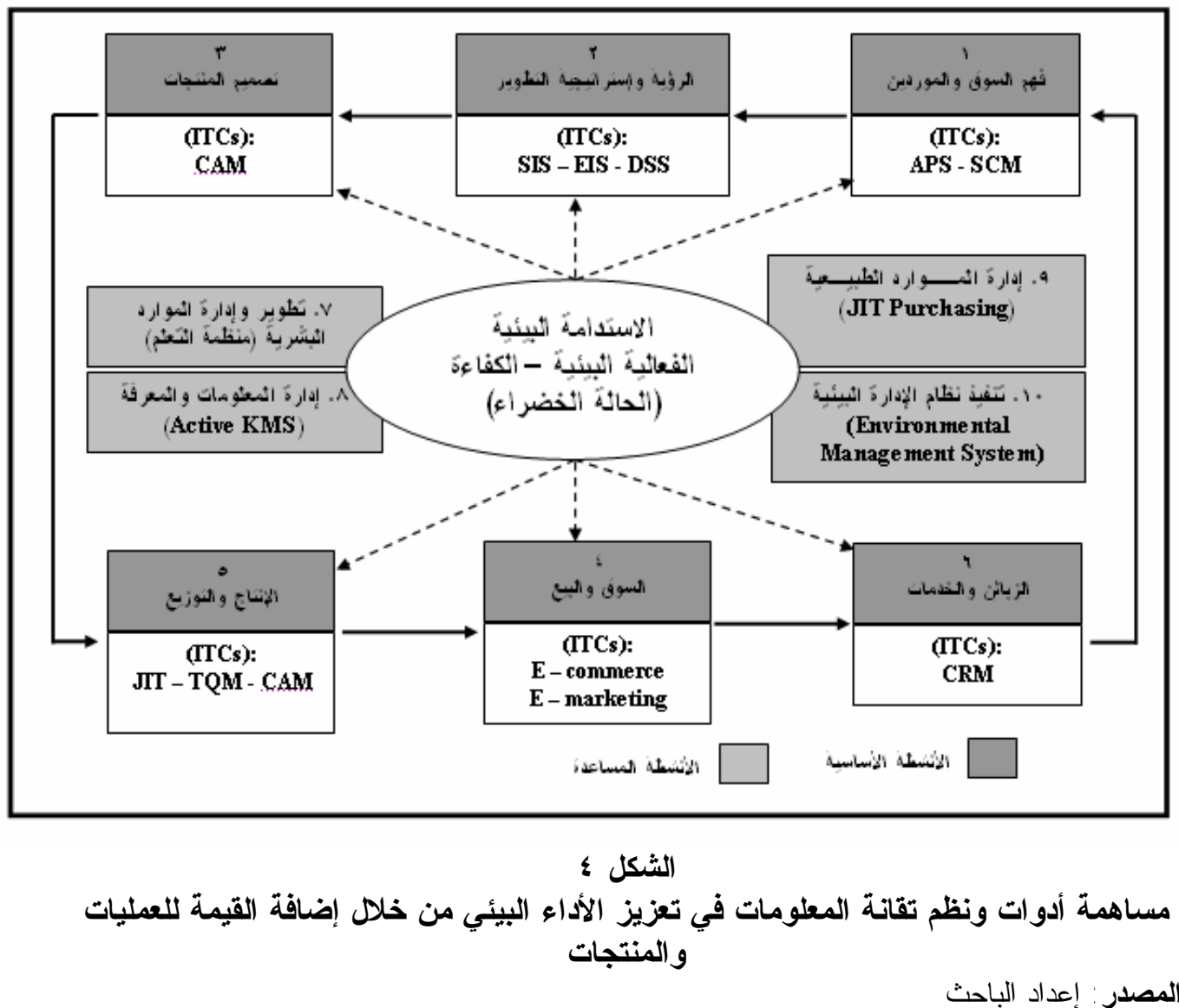

المصدر : إعداد الباحث 


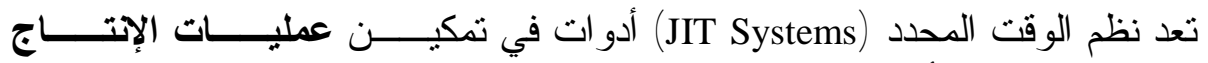

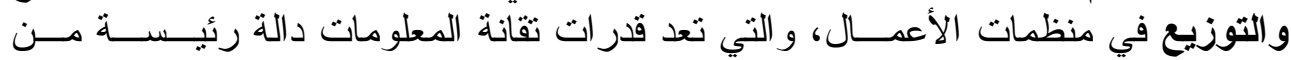

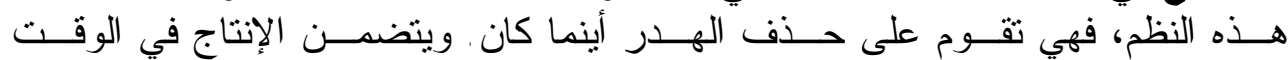

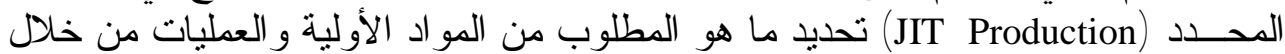

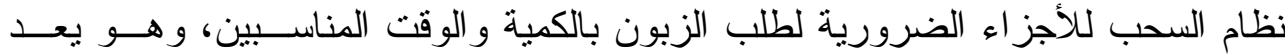

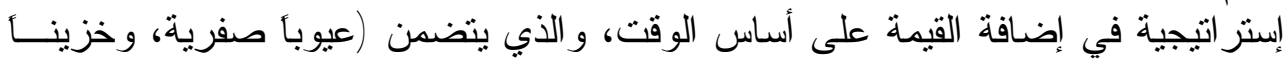

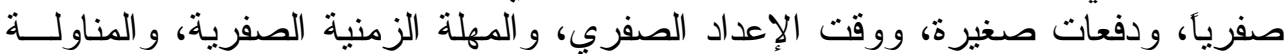

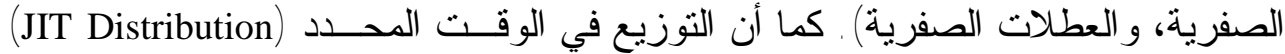

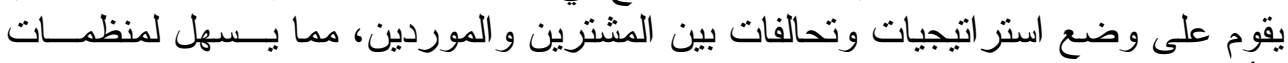

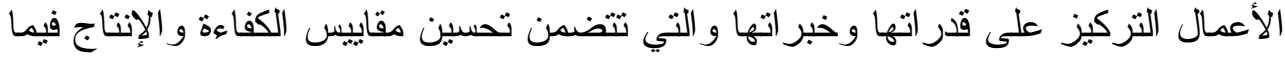

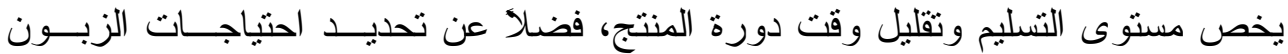

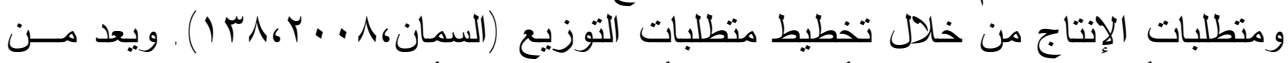

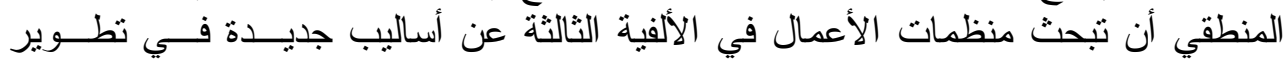

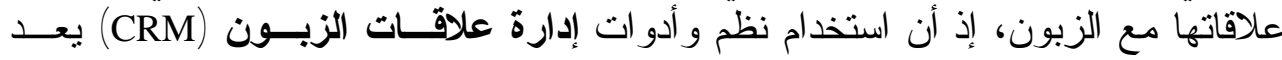

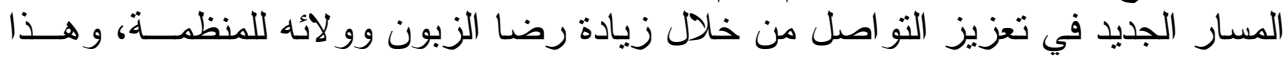

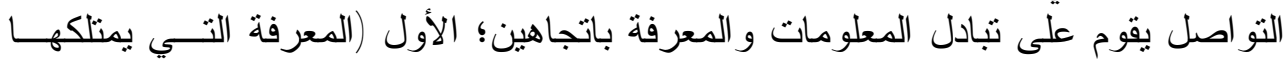

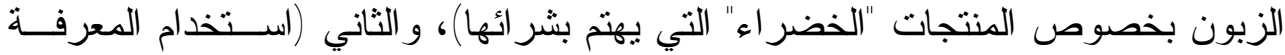

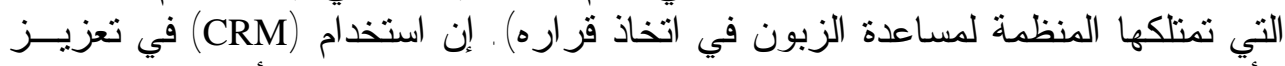

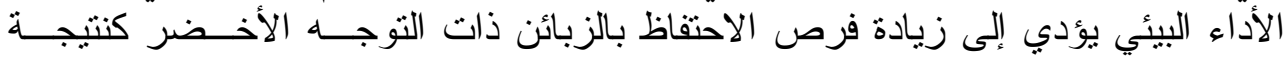

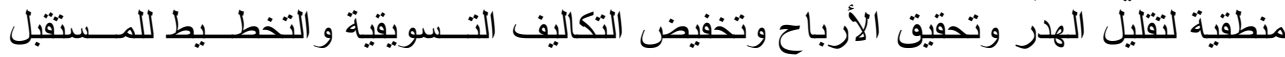

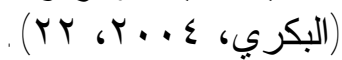

تعد عملية تطوير وإدارة الموارد البشرية (منظمة التعلم)، عملية ضــرورية فـي لئي

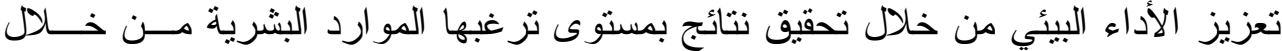

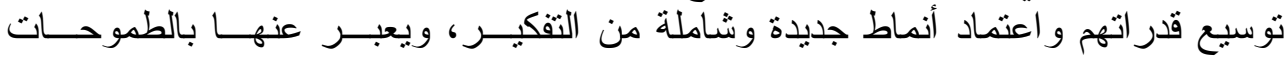

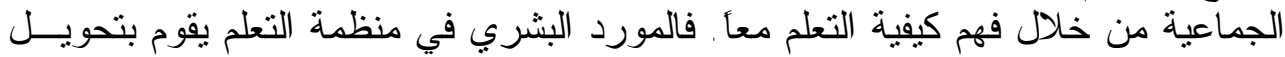

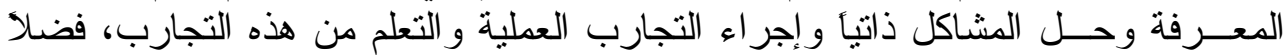

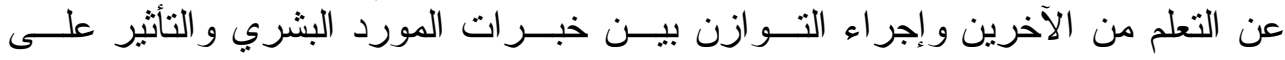

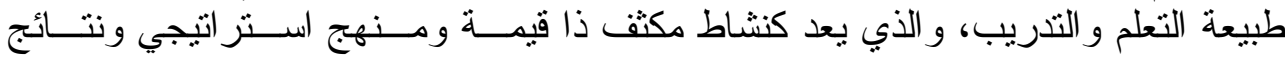

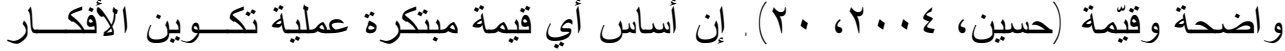

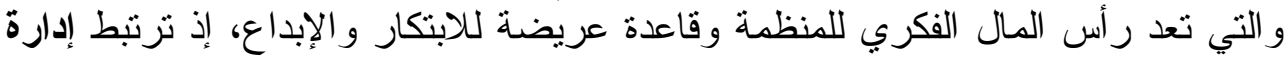

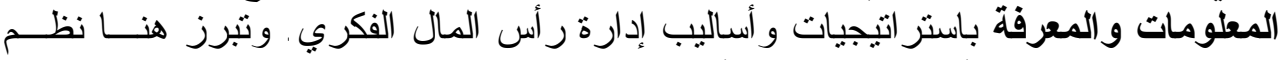

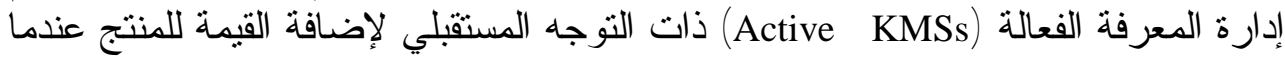

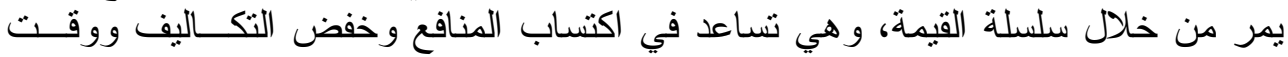

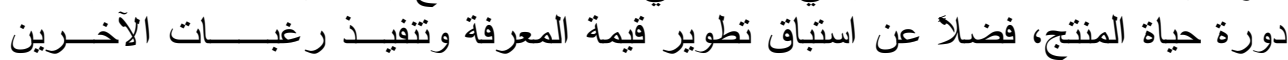

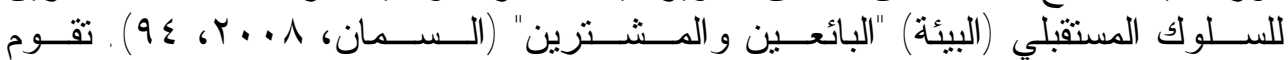

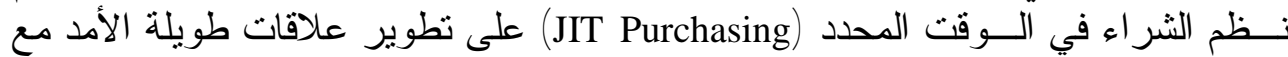

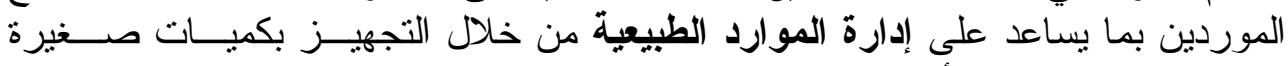

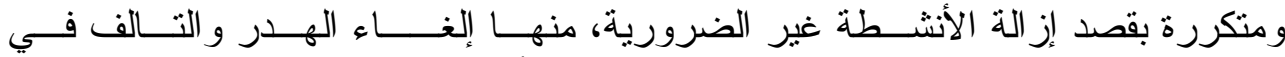

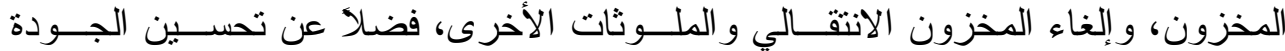


الجبوري[r.9]

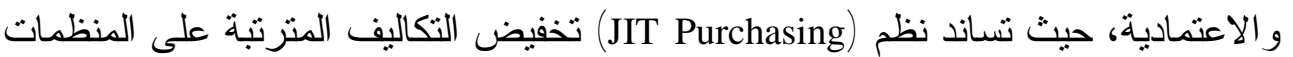

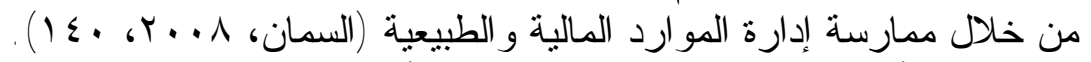

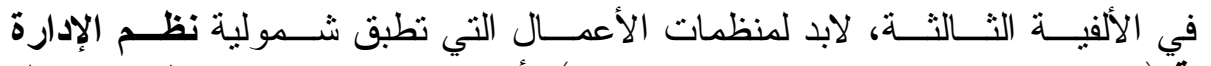

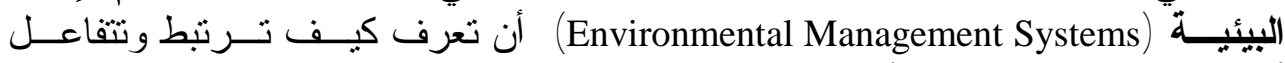
أنشطنها مع البيئة، كتحديد أنواع التأثير ات البيئية المنبثقة من عملياتها المختلفة، و والوسائل

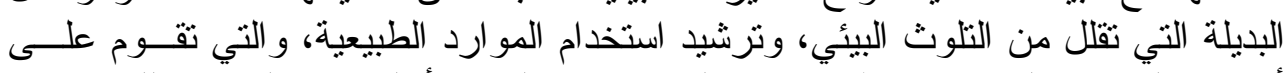

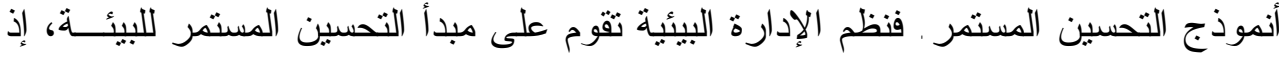

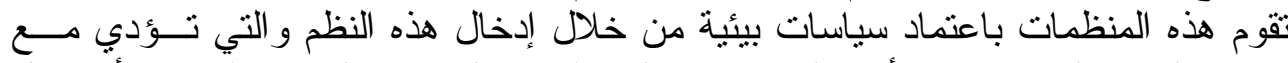

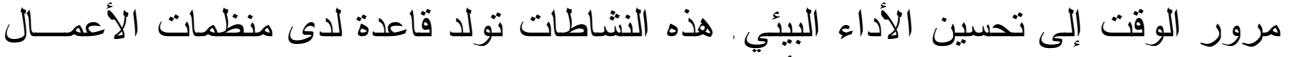

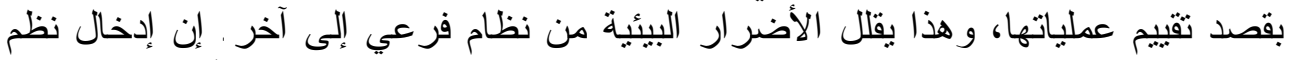

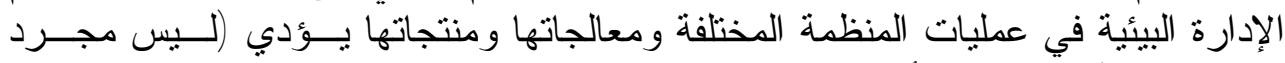

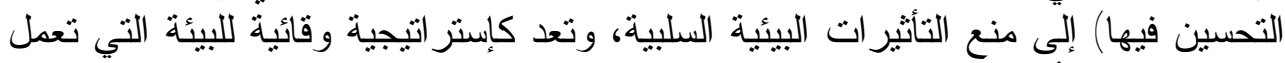

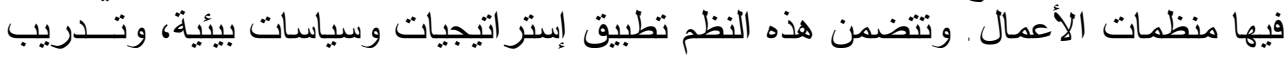

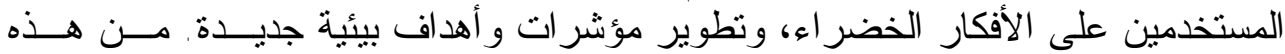

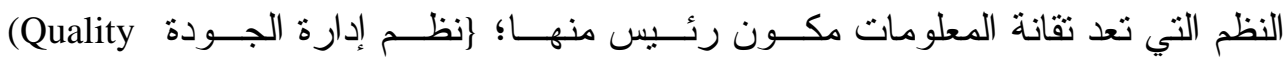
(Management Systems)

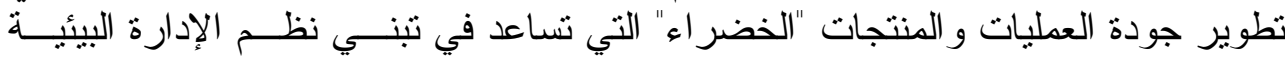

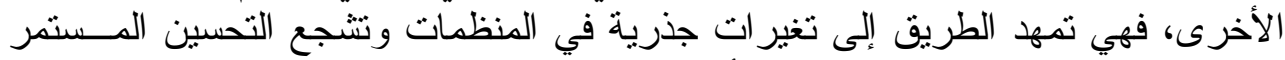

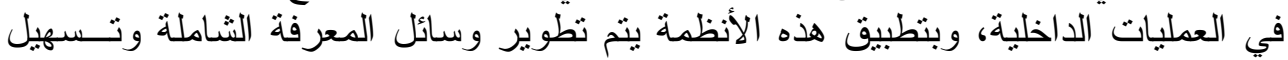

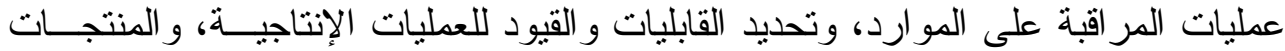

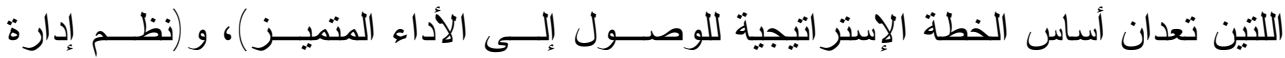

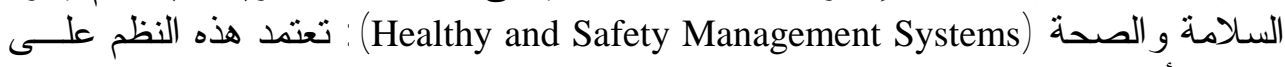

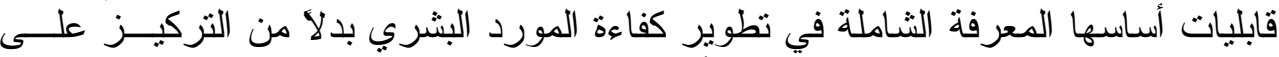

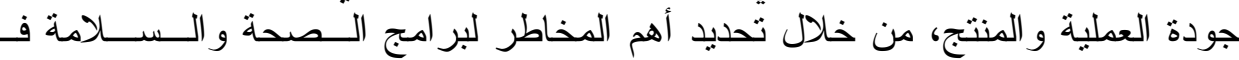

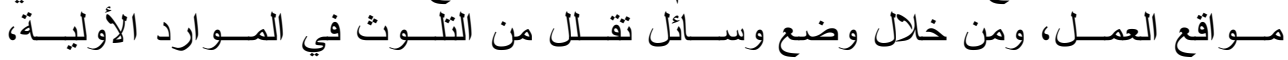
كالموارد الكيمياوية، عليه فإن أهداف هذه النظم تتطابق مع أهداف نظم الإدارة البيئية في تحسين الأداء البيئئ. . (Darnall, et. al., 2006, 10).

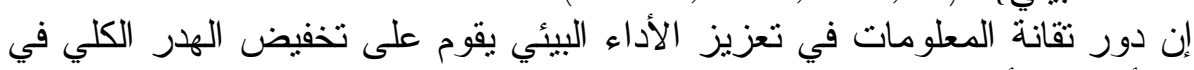

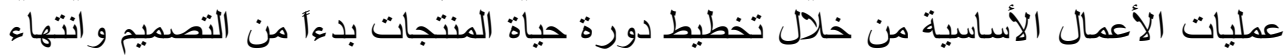

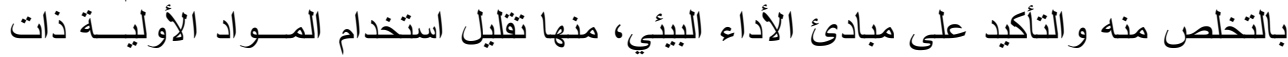

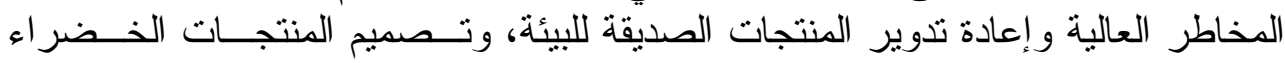

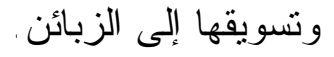

الاستتتاجات و المقترحات

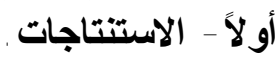

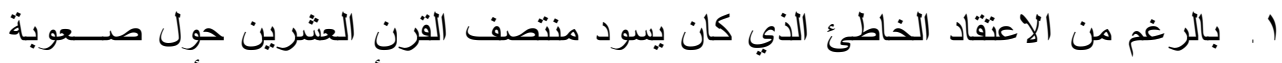

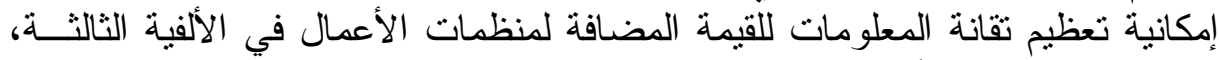

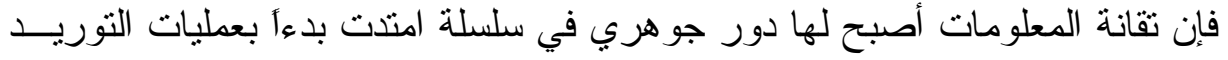


لتتـمل التطبيقات الإستر اتيجية الجديدة و انتهاء بإدارة علاقات الزبائن لتحقيــق قيمــة مضافة للأعمال وتعظيمها الإنئ.

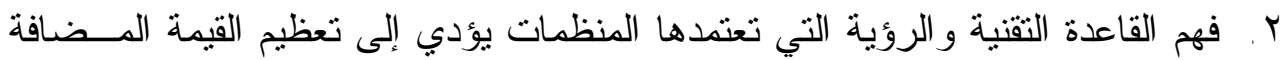

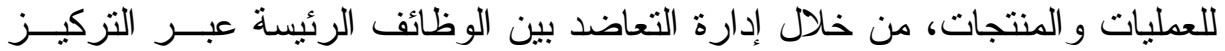

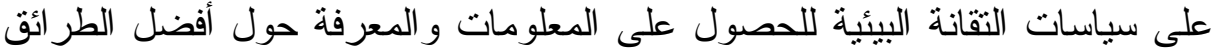

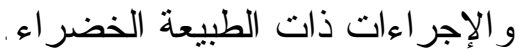

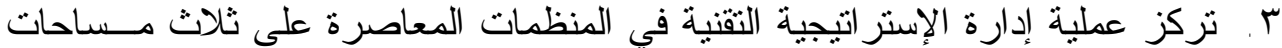

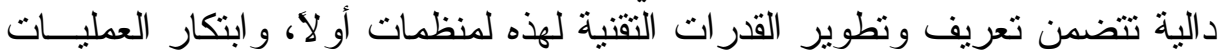

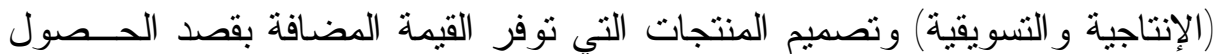

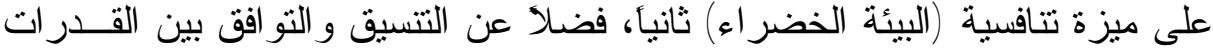

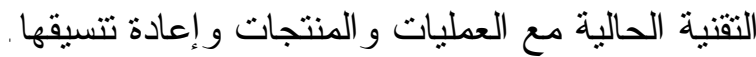

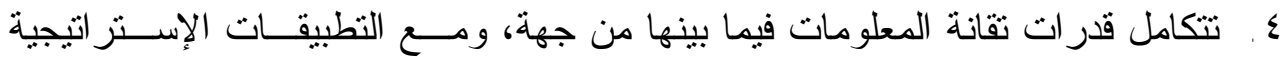

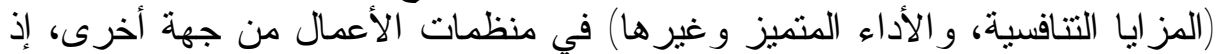

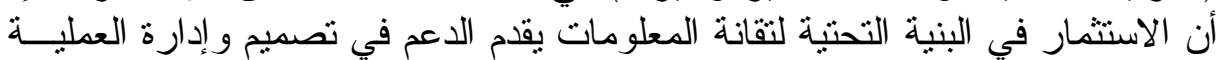

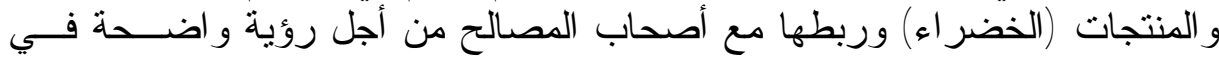
تحقيق الأداء البيئي و الوصول إلى الصى التميز .

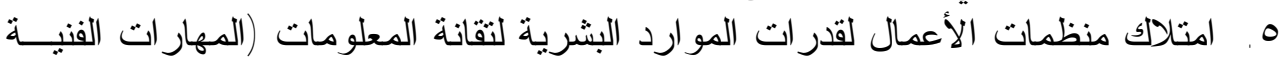

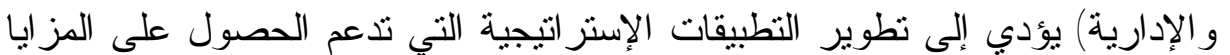

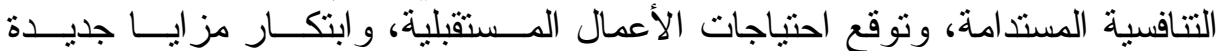

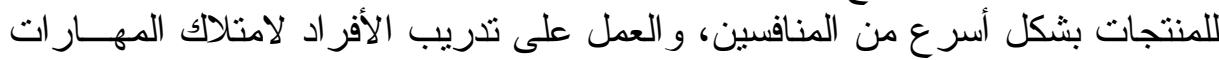
البيئة.

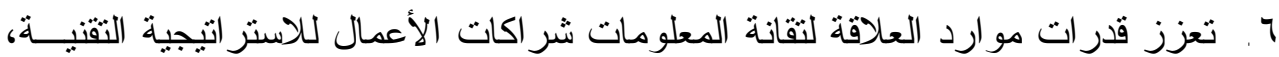

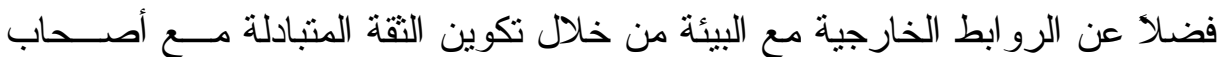

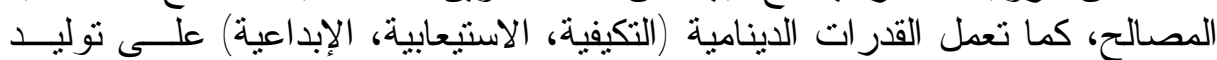

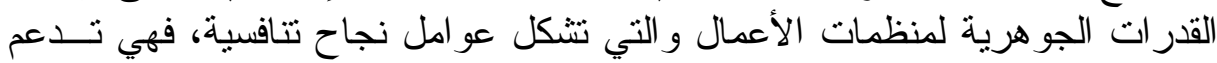

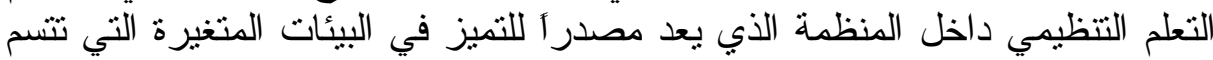
فيها النشاطات المعرفية بأهمية كبيرة بقصد دعم الإدر الك و الاستجابة و التكيف .

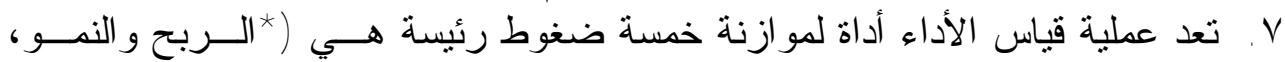

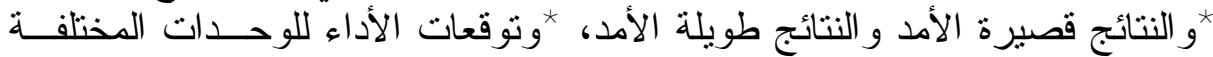

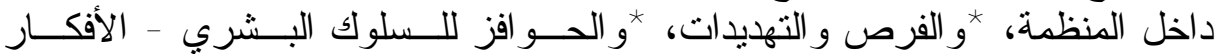

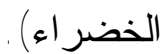

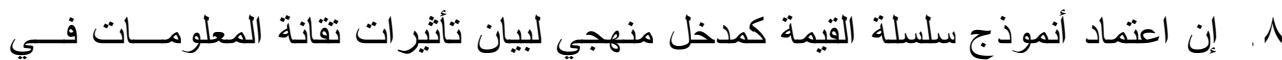

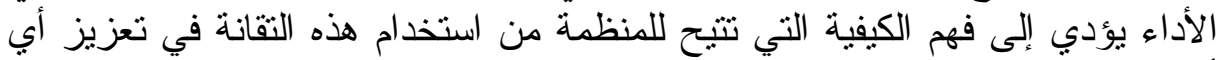

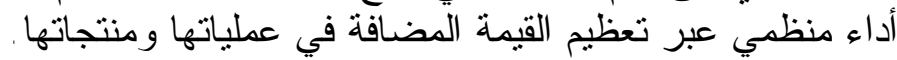

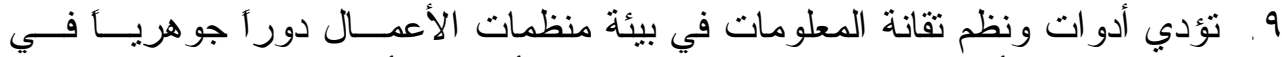

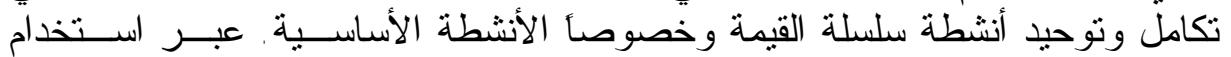

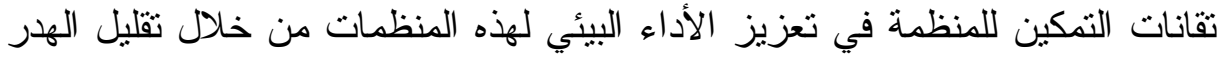

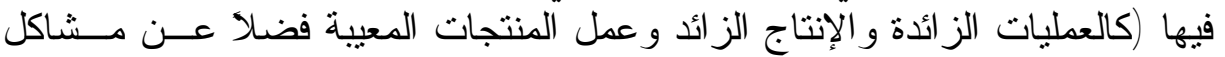


الجبوري[1'

التخزين و النقل و الانتظار و الحركة)، وترشيد الدوارد وهو ما يطلق عليه باقتصاديات

ثانياً - المقترحات

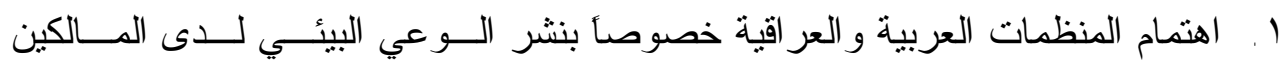

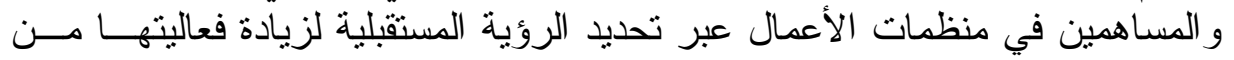

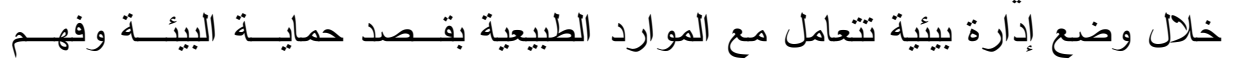

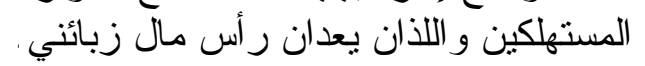

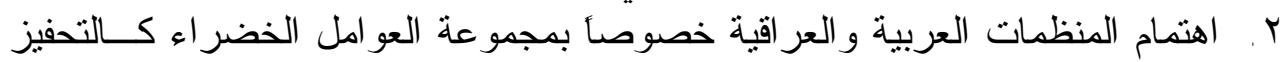

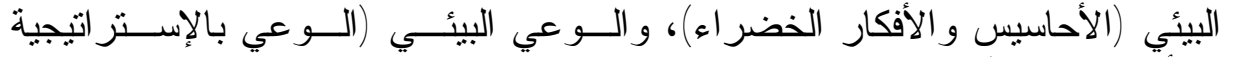

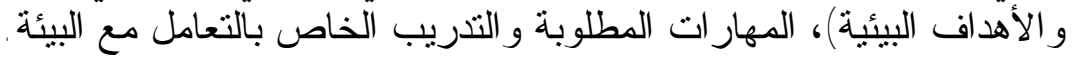

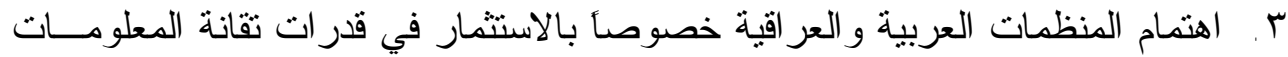

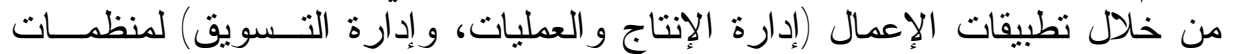
الأعمال التي تدعم حصول لطبات الإعمال على مز ايا تتافسية.

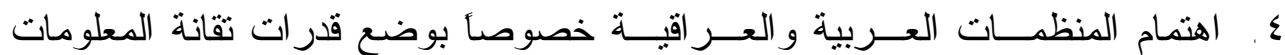

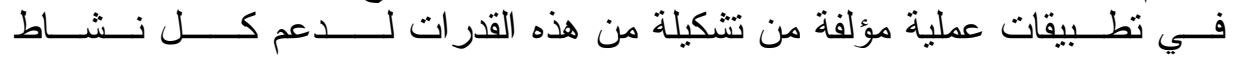

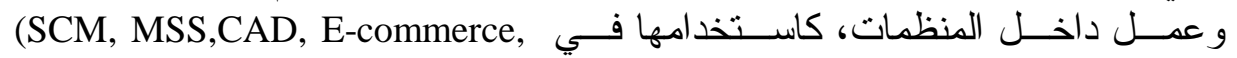
JIT Systems, CRM, KMSs, Environmental MSs)

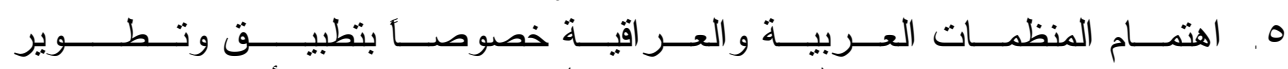

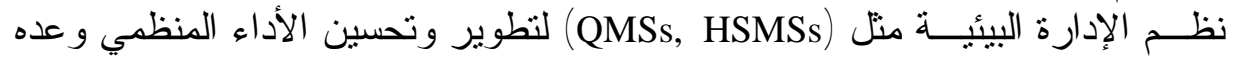
نشاطأ مساعدأ في تعظيم القيمة في منظمات الأن الأعمال.

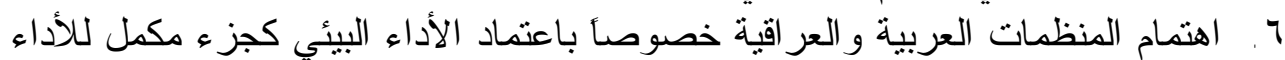

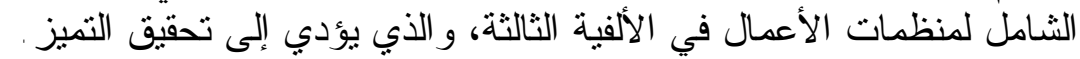

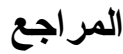 \\ أولاً - المر اجع باللغة العربية}

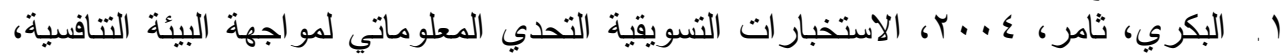

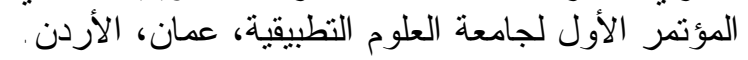

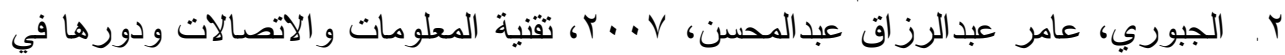

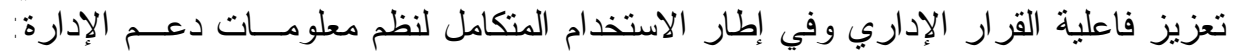

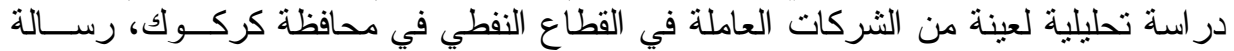

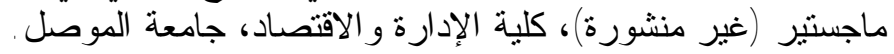

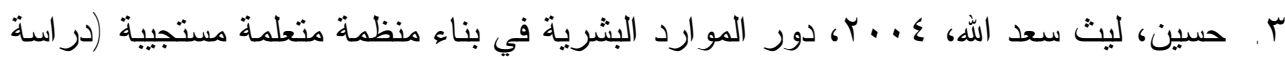

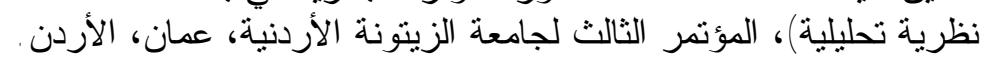

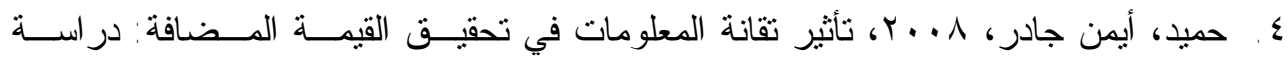

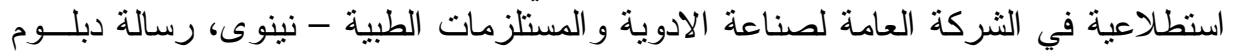

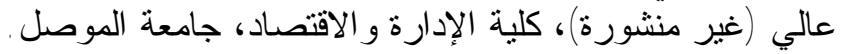

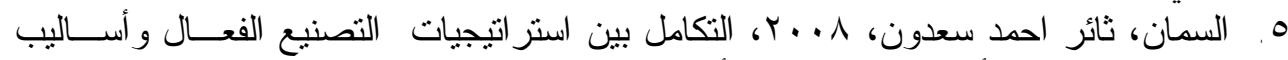

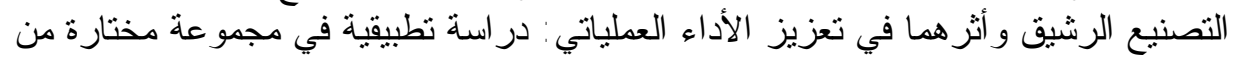




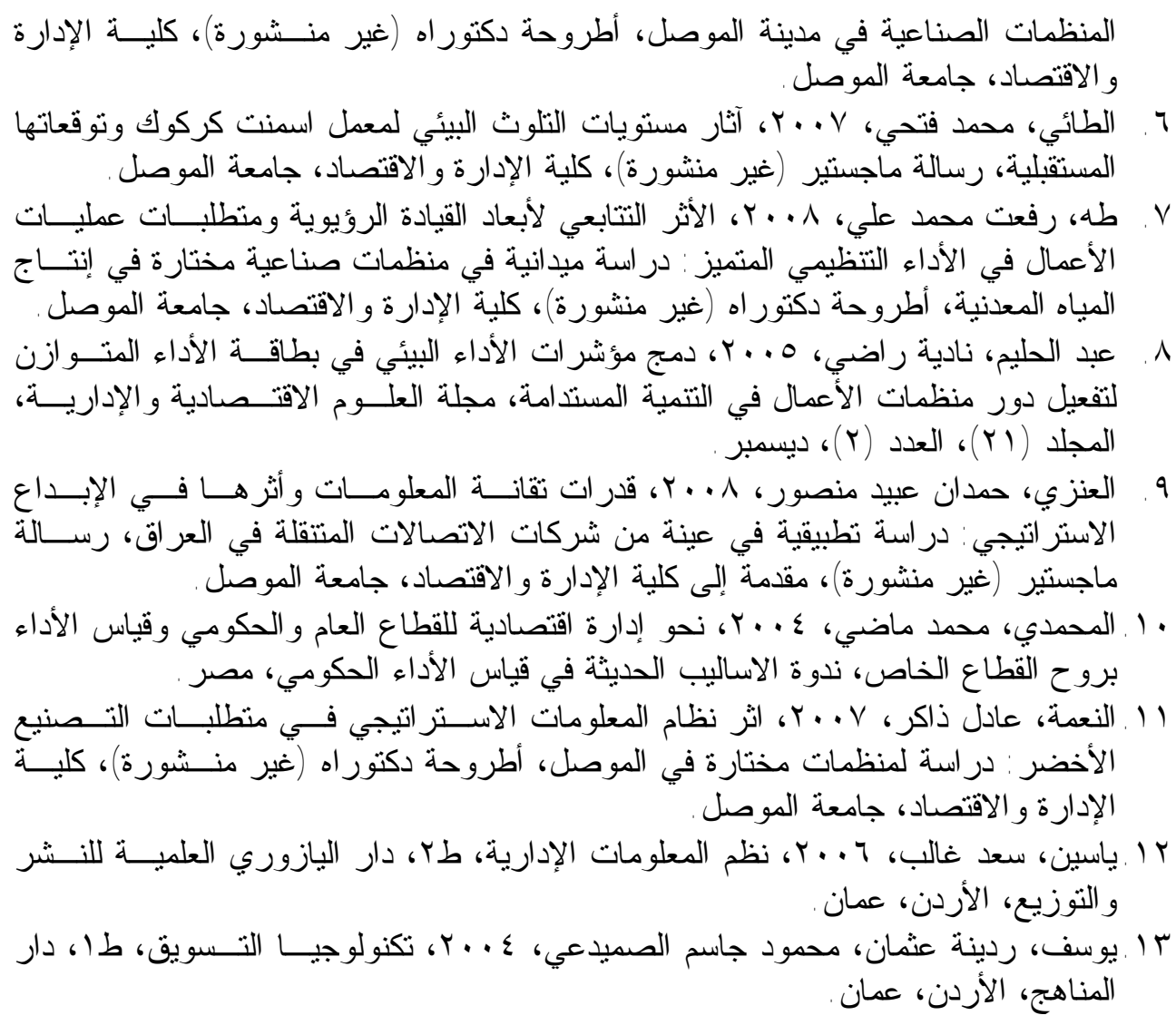

\section{ثانياً - المر اجع باللغة الأجنبية}

1. Adler, P. ,1989, Technology Strategy: A Guide to the Literatures, Management and Policy Journal,Vol.4, JAI Press.

2. Alter, Steven, 1999, Information Systems: A Management Perspective, 3rded, Addison Wesley Longman, Inc, USA.

3. Bendoly E. , A. Soni, M. Venkataramanan, 2004, Value Chain recourse planning: Adding Value with systems beyond the enterprise, Business Horizons, March-April 2004 (79-86).

4. Betz, F., 1993, Strategy Technology Management, McGraw-Hill, New York, USA.

5. Bharadwaj, Anandhi S. , V. Sambamurthy and Robert W. Zmud, 1999, IT Capabilities: Theoretical Perspectives and Empirical Operationalization. 2nd International Conferences on IS ,Charlotte, NC.

6. Bharadwaj, Anandhi S., V. Samhamurthy, R. Zmud, 2002, IT Capability: An Empirical Examination of Construct and its link to performance, Working Paper (Emory University).

7. Bhatt, Ganesh and Varun Grover, 2005, Types of IT Capabilities and their Role in Competitive Advantage: An Empirical Study, Journal of Management IS, Val22, No.2.

8. Clark, E., et. al.., 1997, Building Chang Readiness Capabilities in the IS Organization: insights from the Bell Atlantic Experience, MIS Quarterly, 21(4).

9. Clever, E., M. Lopez, J. Molina, J. Tari, 2006, Environmental Management and Firm Performance: A case study, journal of Environmental Management, (84). 


\section{الجبوري[r|r}

10. Correa, J. , N. Torres, S. Sharma, and V. Morales, 2007, Environmental Strategy and Performance in Small Firms: A Resource-Based Perspective, Journal of Environmental Management, (86).

11. Daft, Richard L., 2003, Management, 6thed, Thomson Learning, Inc, Canada.

12. Darnall, Nicole, Irene Henriques and Perry Sadorsky, 2006, Do Environmental Management Systems Improve Business Performance in an International Setting, http://ssrn.com/abstract=1009265

13. Fang, Gang, Xiao Wu, Zeng-Yuan Wu, 2006 "The Dynamic IT Capability and Firm performance: A Resource-Based Perspective", In : Proceeding of The Fifth International Conference on Machine Learning and Cybernetics, Dalian,13 - 16 August.

14. Faria, Jose A. and Matos, 2006, Availability Analysis and Design of Business Information Systems, International Journal of Business and Information, Vol.1, No.1

15. Haag, Stephen, Mauve Cummings and Amy Phillips, 2007, Management Information Systems For The Information Age, Irwin, McGraw-Hill, Inc.

16. Harrison, Norma and Danny Samson, 2002, Technology Management: Text and International Cases, McGraw Hill, Boston, USA.

17. Hockerts, K., 2001, Corporate Sustainability Management - Towards Controlling Corporate Ecological and Social Sustainability, in Proceeding of Greening of Industry Network Conference, 21 - 24 Jan, Bangkok.

18. Hunger, J. David and Thomas L. Wheelen, 1998, Strategic Management, 6thed, Addison-Wesley, Inc.

19. Kotler, P., 2000 Marketing Management, New Jersey - Prentice Hall, USA.

20. O'Brien, James A., 2003, Introduction to Information Systems, 11thed, Irwin, McGraw-Hill, Inc, USA.

21. Perotto, E., R. Canziani, R. Marchesi and P. Butelli, 2007, Environmental Performance: Indicators and Measurement and Uncertainty in EMS Context: a Case study, Journal of Cleaner Production, (16).

22. Sambamurthy, V. and Robert W. Zmud, 1992, Managing IT for Success: the Empowering Business Partnership, Working paper, Morristown, NJ: Financial Executives Research Foundation.

23. VCAA, Victorian Curriculum and Assessment Authority, 2005, Interdisciplinary Learning Strand Information and Communications Technology, Australia, www.ssrn.com

24. Wade, Michael and John Hulland, 2004, the Resource-Based View and IS Research: Review, Extension and suggestions for Future Research, MIS Quarterly ,28(1).

25. Zhang, Man, 2005, IT Capability, Organizational Culture, and Export Performance, Dissertation Doctor of Philosophy, Collage of Business and Economics, Washington State University. 